NBER WORKING PAPER SERIES

\title{
THE POTENTIAL USE OF IN-HOME SCANNER TECHNOLOGY FOR BUDGET SURVEYS
}

\author{
Andrew Leicester \\ Working Paper 19536 \\ http://www.nber.org/papers/w19536 \\ NATIONAL BUREAU OF ECONOMIC RESEARCH \\ 1050 Massachusetts Avenue \\ Cambridge, MA 02138 \\ October 2013
}

Funding from the ESRC Centre for the Microeconomic Analysis of Public Policy (RES-544-28-5001) at IFS is gratefully acknowledged. The author would like to thank Chris Carroll and participants at the December 2011 NBER-CRIW Conference on Improving the Measurement of Consumer Expenditure in Washington, DC for useful comments; Kantar Worldpanel for supplying the data on which much of the analysis is based; Kate Davies, Gareth Clancy and Neil Price from the UK Office for National Statistics (ONS) for advice on NationalAccounts and Retail Sales data; and Giles Horsfield of the ONS for information on the use of scanners by the ONS. Data from the UK Living Costs and Food Survey 2001/2-2009 are collected by the Office for National Statistics and distributed by the Economic and Social Data Service. Crown copyright material is reproduced with the permission of the Controller of HMSO and the Queen's Printer for Scotland. This work was completed by the author during his time at the Institute for Fiscal Studies (IFS). The views reflected are those of the author and not the IFS, Frontier Economics Ltd, or the National Bureau of Economic Research.

NBER working papers are circulated for discussion and comment purposes. They have not been peerreviewed or been subject to the review by the NBER Board of Directors that accompanies official NBER publications.

(C) 2013 by Andrew Leicester. All rights reserved. Short sections of text, not to exceed two paragraphs, may be quoted without explicit permission provided that full credit, including $\odot$ notice, is given to the source. 
The Potential use of In-home Scanner Technology for Budget Surveys

Andrew Leicester

NBER Working Paper No. 19536

October 2013

JEL No. C42,C81,C83,D12

\begin{abstract}
$\underline{\text { ABSTRACT }}$
This paper considers the potential role of in-home scanners as a method of data collection for national budget surveys such as the Consumer Expenditure Survey. A detailed comparison is made between scanner data and diary-based budget survey data for food at home in the UK. Levels of recorded spending are lower in scanner data for all commodities, but patterns of spending are similar. A large part of the difference is explained by households in the scanner survey failing to record any food spending in a given week. The gaps are widened once demographic differences between the surveys are controlled for. There is clear evidence that short-term diaries do not accurately capture household food spending patterns given infrequency of purchase for some commodity groups. Conditional on store choice, demographics play little role in explaining food spending patterns in scanner data. This suggests that attempts to impute detailed spending patterns from aggregate store-level spending would be difficult.
\end{abstract}

Andrew Leicester

Frontier Economics Limited

71 High Holborn

London WC1V 6DA

United Kingdom

www.frontier-economics.com

andrew.leicester@frontier-economics.com 


\title{
The potential use of in-home scanner technology for budget surveys
}

\author{
Andrew Leicester ${ }^{\dagger}$
}

Institute for Fiscal Studies

\section{Introduction}

In-home scanner expenditure data are collected via a barcode reader installed in the home. ${ }^{1}$ Information about purchases is collected when participants scan the barcodes of any items brought home. Matched with information on prices, stores and the characteristics of participants, such data offer in principle a detailed, complete record of purchasing behaviour. Scanner data have long been used for marketing studies, and increasingly in the economics literature to explore questions relating to consumer, retailer and manufacturer behaviour (recent examples include Griffith et al, 2009; Broda et al, 2009 and Aguiar and Hurst, 2007). For researchers, the appeal of scanner data lies both in the detailed purchase information and in the fact that the data are typically longitudinal (see Parker et al (2013) for a discussion of the virtues of longitudinal data for research purposes). Panel expenditure datasets are comparatively rare. National budget surveys are usually cross-section, and measures of spending in panel data (such as the UK Household Longitudinal Study) tend to be limited and highly aggregated. Panel data offer the chance to explore changes in purchasing behaviour in response to shocks or policy interventions. For example, Harding et al (2012) use scanner data to explore the impact of changes in cigarette taxes on prices and consumption. There is also growing interest amongst policy makers in what can be learned from scanner data. The UK Department for the Environment, Food and Rural Affairs carried out a study of ethical shopping decisions in conjunction with a commercial scanner data collector (DEFRA, 2011). Scanners are also starting to feature in non-commercial surveys: the US Department of Agriculture is planning to use scanners, alongside other data collection methods, to record detailed food purchase behaviour as part of the Food Acquisition and Purchase Survey (FoodAPS). ${ }^{2}$

The main aims of this paper are to consider what role scanner data could play for collecting household expenditure information as part of budget surveys such as the US Consumer Expenditure Survey (CE) or the UK Living Costs and Food Survey (LCF). ${ }^{3}$ A

\footnotetext{
${ }^{\dagger}$ Funding from the ESRC Centre for the Microeconomic Analysis of Public Policy (RES-544-28-5001) at IFS is gratefully acknowledged. The author would like to thank Chris Carroll and participants at the December 2011 NBER-CRIW conference on Improving the Measurement of Consumer Expenditure in Washington, DC for useful comments; Kantar Worldpanel for supplying the data on which much of the analysis is based; Kate Davies, Gareth Clancy and Neil Price from the UK Office for National Statistics (ONS) for advice on National Accounts and Retail Sales data; and Giles Horsfield of the ONS for information on the use of scanners by the ONS. Data from the UK Living Costs and Food Survey 2001/2-2009 are collected by the Office for National Statistics and distributed by the Economic and Social Data Service. Crown copyright material is reproduced with the permission of the Controller of HMSO and the Queen's Printer for Scotland. Views and mistakes are those of the author alone.

${ }^{1}$ Distinct from 'storescan' data collected from items passing through tills. A previous NBER volume, Feenstra and Shapiro (2003), considered the possible usefulness of store-level scanner data for measuring prices and price indices. There are clearly complementarities between store-level and consumer-level scanner data.

See http://www.ers.usda.gov/Briefing/SNAP/food_aps.htm and Cole (2011).

${ }^{3}$ The discussion here represents a condensed version of Leicester (2012) which provides further detail and analysis in a number of areas.
} 
limited role is validation. Comparisons of budget survey data to aggregate data have led to increasing concern about the quality of survey expenditure data. However, there has been little scope to make micro-level comparisons since few surveys (besides the budget survey itself) collect detailed spending information. Scanner data offer such a possibility. They also record household expenditures over long periods of time, which allows us to explore how the time-limited nature of budget surveys (the UK LCF records spending over just two weeks) affects the spending patterns which are observed. ${ }^{4}$

A more involved role for scanner data in budget surveys might be as part of the data collection process itself (Mathiowetz et al, 2011). This could involve scanners being used in place of or alongside current survey methods such as paper diaries and recall questions. The key question for statistical agencies is to understand the modal effect of using scanners on the data which is obtained. Comparative studies between scanner and other expenditure data offer some insights here, but fully disentangling modal effects from other differences between surveys (such as demographic and sampling differences) is likely to require experimental methods. Scanner data could also be used for imputation. As a way to reduce respondent burden, some commentators (e.g. Tucker, 2011) have suggested asking only limited questions about aggregate category-level expenditure in budget surveys. Information from other sources such as scanner data could then be used to break these down into detailed spending patterns using imputation methods.

This paper focuses on how statistical agencies might make use of established scanner surveys collected by market research companies. An alternative would be for statistical agencies to establish and maintain their own scanner data. Whilst costly, this would offer a number of advantages. It would override concerns about outsourcing part of the data collection process to commercial organisations. It would allow controlled experimentation to explore modal effects. It would ensure that the information on demographics and the statistical properties of the data were of sufficiently high quality to be useful for national statistics and research purposes. We offer some thoughts on the scope for establishing a separate scanner survey in the conclusions.

The rest of the paper is organised as followed. Section 2 describes the datasets which underlie most of our analysis: the UK LCF and scanner data from Kantar Worldpanel. Section 3 briefly surveys the existing literature comparing scanner data to other data. In Section 4, we compare food expenditures reported in scanner data, budget survey data and national accounts data. We assess the impact of using budget shares taken directly from the budget survey and scanner data as basket weights in calculating food price indices, in place of current weights derived from aggregate expenditure data. We also explore how expenditure patterns vary with the duration for which we observe household spending. Section 5 explores the prospects for using detailed spending patterns from scanner data to impute budget shares for households when all we observe are total expenditures. Section 6 offers some overall thoughts and conclusions.

\footnotetext{
${ }^{4}$ This has important implications for attempts to use short-run spending information to make inferences about the distribution of living standards (for example Attanasio et al, 2006; Brewer et al, 2006)
} 


\section{Data}

\subsection{Living Costs and Food Survey}

The Living Costs and Food Survey (LCF) is the main UK source of household budget information. Collected by the Office for National Statistics (ONS), it is an annual crosssection of around 6,000 households. The survey has been renamed twice, each time undergoing some structural changes (though the coverage and main methods of the data have remained essentially unchanged). Until 2001 it was the Family Expenditure Survey (FES). It then merged with a second, related, survey recording nutritional intake at the household level and became known as the Expenditure and Food Survey (EFS). It was then renamed the LCF in 2008. We use LCF throughout to refer to this data. Sampling is carried out via stratified random sampling, with strata based on region, socio-economic status and car ownership. Northern Ireland is over-sampled but survey weights are provided to ensure the weighted sample is nationally representative. The response rate in 2010 was 50\%; this has declined substantially in recent years.

The data are made up of two main parts. The first is a two-week diary issued to all household members aged 16 and over. Children aged 7 to 15 receive a simplified diary. ${ }^{5}$ Participants record all their expenditures over the period, attaching till receipts where possible to reduce the extent to which handwritten records of spending have to be maintained. A $£ 10$ incentive ( $£ 5$ for children) is paid for successful completion of the diary. Household members are also interviewed to obtain detailed demographic and income information, as well as data on large irregular purchases (such as furniture and holidays) and regular expenses like household energy and housing payments. Data from the diary and the questionnaire are coded into a large number of separate spending items for each household, all of which are reported on a per-week basis. Details of methods and the main findings are collated each year into an ONS publication Family Spending. ${ }^{6}$

\subsection{Kantar Worldpanel}

Kantar are a market research company who operate a number of surveys of consumer behaviour, including Worldpanel which is collected in a number of countries. In Britain, one use of Worldpanel data is to estimate market shares of the major supermarkets. ${ }^{7} \mathrm{~A}$ large, representative sample of households is active in the data at any one time. Until 2006 , the average sample size was around 15,000; since then it has risen to around 25,000. Participants are recruited from a range of address sources using quota sampling, though Northern Ireland is excluded. Household weights are derived which ensure that the weighted sample (over a particular period of observation) of active households is representative based on household size, housewife age, social class and region.

Households can participate for as long as they wish, and receive points redeemable for consumer goods as an incentive to do so. Participating households are issued with a barcode reader which is installed in the home, and are asked to record the purchases of all barcoded products brought home. Our data contain information on 'fast-moving consumer goods' - essentially food and grocery products, including things like cleaning

\footnotetext{
${ }^{5}$ Children were first asked to keep a diary in 1995/6. We use LCF data including spending reported by children. since in principle children's purchases should also be captured in scanner data.

${ }^{6}$ The report on the 2010 LCF data is available from http://www.ons.gov.uk/ons/rel/family-spending/familyspending/family-spending-2011-edition/family-spending-2011-pdf.pdf.

${ }^{7}$ See http://www.kantarworldpanel.com/.
} 
products and personal care items. Alcohol (purchased off-licence) is included but tobacco is not. Leicester (2012) estimates that the set of products contained in the Worldpanel data make up something like $18 \%$ of all non-housing expenditure. ${ }^{8}$

Purchases from all retailers, not just supermarkets, are in principle recorded, as are online grocery purchases. The data are at the transaction level - typically up to a million separate transactions are recorded in a week of data. Detailed information on the characteristics of the products purchased is recorded, including the macro-nutritional composition of food items. Until 2006, all households were asked to report non-barcoded food and grocery purchases using a booklet of generic barcodes. Details of the product characteristics for these items (such as weight, country of origin, flavour and so on) were also entered manually via the scanner device. This increases responder burden, and so from 2006, some households were no longer required to report these items and were issued with a simpler scanner unit. Information on the price paid is obtained from till receipts which are mailed in to Kantar who match the price to the purchase record. Where no receipts are available, prices are taken from centralised databases of store- and product-specific prices, or otherwise imputed. The data also record any promotional deal attached to a purchase. Information on the store visited is recorded by the participants.

Household demographic characteristics are recorded in a baseline telephone interview, and then updated every nine months or so. The set of demographic questions is typically much less comprehensive than those recorded in the LCF, and an interview is held only with the 'main shopper' in each household rather than with each household member separately. All household members should, though, report their expenditures.

\subsection{Mapping Kantar expenditure data to LCF data}

The Kantar data are reported at the barcode level. There are more than 568,000 individual products. The LCF records household-level expenditures in a large number of fairly disaggregated expenditure codes. Making comparisons requires us to match individual products from the Kantar data into equivalent LCF expenditure codes. We use detailed information on the sorts of products which make up each expenditure code supplied with the LCF documentation, and the detailed product characteristics in the Kantar data, to make this match as accurately as possible, though inevitably there is some judgement in this process. Having created this mapping, we then further aggregate expenditures into commodity groups to match those defined in the UK Consumer Prices Index (CPI). This definition matches the level at which disaggregated expenditure information is available from the National Accounts, making comparisons to aggregate data more straightforward. Our analysis covers only food and drink purchases.

In principle, of course, when making comparisons across datasets, we could look at much more disaggregate commodity groups. The LCF includes 73 distinct food and drink codes, so this would be the most disaggregate comparison possible. ${ }^{9}$ Finer disaggregation may be useful to understand exactly where differences between scanner and other datasets arise and what might be driving that. However, as discussed in Leicester and Oldfield (2009), the more disaggregate the comparison the less confident we can be about the mapping between Kantar and LCF expenditures. The problems are particularly acute

\footnotetext{
${ }^{8} \mathrm{His}$ analysis suggests that just over one-third of all spending would be amenable to in-home scanning.

${ }^{9}$ Statistical agencies would, of course, have access to even more disaggregate budget survey data.
} 
where it is not clear in the Kantar product information whether meats, fish, fruits and vegetables are 'fresh' (largely meaning unadulterated, so including e.g. plain frozen fish fillets) or 'processed' (largely meaning they are pre-prepared or flavoured in some way). Fresh and processed products have distinct LCF codes but fall into the same CPI groups, such that at the CPI level of aggregation there is more certainty that we are comparing like-with-like (spending on 'fish' or 'meat', say).

\section{Previous research}

This paper adds to a small but growing literature exploring data quality issues for scanner data. A number of previous studies have compared scanner data to budget survey data. Any regularities which emerge from these comparisons would be strongly suggestive of survey mode effects from the use of scanners. However, definitive statements about modal effects would require experimental evidence which held, as far as possible, other factors constant. Such evidence does not appear to exist at the moment. A valuable contribution from statistical agencies collecting their own scanner survey data would be the ability to carry out controlled experimental analysis.

The strongest common finding is that average expenditure levels are markedly lower in scanner data than in budget survey data. Duly et al (2003) compare AC Nielsen Homescan data to CE Diary Survey data from 2000. Overall, scanner expenditures were about twothirds of the budget survey level. Alcohol and tobacco expenditures were about half the budget survey level in the scanner data. Using British data from Kantar Worldpanel and the Living Costs and Food Survey, Leicester and Oldfield (2009) find that, in 2005, weekly total food expenditures in scanner data were about $20 \%$ below those in budget surveys on average. Using comparisons of nutritional intake, Griffith and O'Connell (2009) find that the number of calories reported in British scanner data were around $23-52 \%$ lower than in budget survey data depending on the household type studied. They find strong evidence, as do we below, that a large part of this gap is driven by weeks in which no food at all is purchased in scanner data, though it does not account for all of the difference.

Previous studies have not found common results on the extent to which this 'underreporting' in scanner data is consistent across product categories. Using US data from 2002-2005, Zhen et al (2009) find scanner expenditures of 50\% below CE levels for a number of commodity groups, particularly categories where non-barcoded items are common such as meat, fruit, vegetables and fish. For groups where almost all items are barcoded, such as confectionery and processed fruits, they find essentially no differences in expenditure. In contrast, Leicester and Oldfield (2009) find little evidence in British data of significant differences across groups, with the exception of alcohol. One likely reason for the difference is that in the US data, only $20 \%$ of households were required to record non-barcoded items whereas all households in the British data were asked to do so. Leicester and Oldfield (2009) can explore this directly, since from 2006 only some households were asked to report non-barcoded purchases. They find this has a substantial effect. Households reporting their non-barcoded purchases recorded 24\% less expenditure on fruit than found in budget surveys; those not reporting them recorded $44 \%$ less spending.

There is also disagreement on the extent to which demographic differences between samples help account for the lower expenditures in scanner data. Zhen et al (2009) use a 
regression model to strip out observable demographic differences between datasets and argue that, in combination with the non-barcoded items issue, they largely accounts for the spending differences. Leicester and Oldfield (2009) conclude that demographic differences accentuate the gaps between datasets. They estimate a 'propensity weight' for each household in the Worldpanel data which reflects how similar its observed demographics are to those of LCF households. Using this weight, they find that the average gap between total spending in the two datasets rises from $20 \%$ to $25 \%$. These contrasting findings probably result in part from differences across countries in the relative sample compositions between scanner and budget survey data. For example, in the US, scanner households appear to have fewer members on average than those in the budget survey (Huffman and Jensen, 2004) whilst the reverse is true in Britain (Leicester and Oldfield, 2009). The contrast may also reflect differences in the set of observable demographics common to scanner and budget survey datasets. The demographic information available in scanner data is often much less comprehensive than that found in budget surveys. Kantar Worldpanel, for example, did not routinely collect information on household incomes until 2008, and even then only a banded measure of gross total income is collected from a single question asked of the main shopper. By contrast the LCF contains detailed questions on unbanded incomes by source for each household member. Similarly, information in the Worldpanel on education and employment status are not consistently collected for each adult household member, and common variables like tenure are also not always reported.

A particular problem noted by Leicester and Oldfield (2009) was poor reporting of demographic transitions over time in the Kantar data. For example, using data from 2002 to 2005 , they find that amongst a sample of households headed by someone employed and aged 50 or over, just $2.9 \%$ were observed to be unemployed a year later. This compared to $11.4 \%$ of a similar sample constructed from the British Household Panel Survey (BHPS), the main panel data set in the UK. There does not appear to be similar evidence from any study of other scanner panels which would shed light on whether this issue was common to scanner data in general or particular to the Kantar Worldpanel.

The main lessons from these findings seem to be that scanner data record less spending than budget surveys, but differences in methods across scanner datasets lead to different conclusions about the extent to which this is driven by observable factors rather than being a modal effect of scanner data per se. Thus any statistical agency (or indeed researcher) planning to use scanner data ought to be aware in detail of the methods that underlie its collection and what that might mean for the data which are collected. There would appear to be a strong case for collaboration between statistical agencies, researchers and data collectors to understand better these issues. Without experimental methods, the next best approach to tease out modal effects may be to try and make comparisons of scanner and budget survey data across countries which follow, as closely as possible, identical methodologies to see which findings are robust.

Aside from comparisons to budget survey data, some papers have attempted to explore reporting issues in scanner data more directly. Einav et al (2008) perform a detailed matching exercise of shopping trips at a particular store, comparing purchases reported in Homescan data to what should be the same shopping trips in loyalty card records. They find that $20 \%$ or so of trips recorded in Homescan were not found in the retailer data, and that around half the trips that were reported in the retailer data were not observed in 
Homescan. On matched trips, the scanner data reported on average $10-15 \%$ fewer items, mostly small consumables which may be consumed before entering the home. The authors found significant problems in reporting prices in scanner data. The price reported in the Homescan record failed to match the loyalty card recorded price about half the time. However this appears to be a particular problem with the way in which prices are imputed into Homescan data based on centralised records of chain-week level prices. This means store- or consumer-specific prices are missed in Homescan. In British Worldpanel data, prices are taken from till receipts and are rarely imputed. ${ }^{10}$ Einav et al (2008) recommend that a similar approach be adopted for Homescan.

With in-home scanners, there may concern about people taking some time to adapt to the technology before they report reliable data. Leicester and Oldfield (2009) find that reported expenditures were highest in the first few weeks of participation. After about 6 months, households spent about 5\% less than in their first week on average. This might be evidence of survey 'fatigue', with households being less assiduous about reporting all their spending after the initial novelty wears off. It might also be evidence of a settling-in process in which households make small errors early on (multiple recording, say) which inflate expenditures relative to their true values. It could also be a genuine behavioural reaction to participation. For statistical agencies thinking about scanner data for budget surveys, the interesting comparison is with the current survey approach. Ahmed et al (2006) find that in the Canadian Food Expenditure Survey, spending drops by $9 \%$ between the first and second week on average.

A further issue relates to quota sampling methods used in scanner data (Tucker, 2011; Zhen et al, 2009; USDA, 2009; Harris, 2005) rather than random probability or stratified sampling used in budget surveys. Westat (2011b) and Perloff and Denbaly (2007) are both critical of commercial scanner data collectors for releasing little information on sampling methods, response rates, attrition rates and so on, and suggest caution in relying on existing scanner data for these reasons.

A final point relates to unobservable differences in the characteristics of households who participate in scanner data and budget surveys. If significant, such differences could have important repercussions for spending records and researchers. Lusk and Brooks (2011) find that households in two large US scanner samples, Homescan and IRI, appear to be more price responsive than the population at large, even conditional on observable characteristics. They offer two possible explanations. Firstly, participating in scanner data may make households more aware of their purchasing behaviour and thus more price sensitive. Secondly, those who agree to participate in scanner data may be a self-selected sample of more price conscious households. Of course, these findings do not tell us whether the participation and self-selection effects are greater in scanner data than in budget surveys, which would be an interesting extension. A fascinating study would be to estimate demand models using budget survey data and scanner data aggregated to the same level to see whether they give similar results.

\footnotetext{
${ }^{10}$ Where receipts are not sent in, imputation methods may be used. Since national supermarket chains in the UK all use national pricing, this imputation should still capture chain-level deals and promotions, though individual discounts from coupons or loyalty cards would be missed.
} 


\section{Comparing scanner and other expenditure data}

Surveys of household expenditure are prone to error. Participants could deliberately or accidentally mis-report their purchases, or change their usual shopping behaviour as a result of participation. Data validation is therefore vital. Without any clear way to obtain a 'gold standard' benchmark of actual expenditures against which to compare surveys, the most promising approach to validation is to compare data sources against one another to see whether they provide different impressions of spending levels, patterns and trends.

In this section, we make two distinct sets of comparisons. Firstly, we compare survey data from Kantar Worldpanel and the LCF to aggregate data from the ONS National Accounts. Secondly, we make micro-level comparisons between the two surveys. In each case, we explore not just total spending but also expenditure patterns. Differences in total spending will matter for issues like living standards and inequality where spending is used as a measure of well-being. But in some cases it is the pattern of spending that matters - for example, in deriving expenditure weights for price indices or estimating demand models. Comparisons of both are therefore important.

\subsection{Comparison to national expenditure aggregates}

Several recent papers explore the quality of budget survey data by comparing them to aggregate expenditure data. Examples in the US include Triplett (1997), Slesnick (2001), Attanasio et al (2006), and in the UK include Tanner (1999), Blow et al (2004), Attanasio et al (2006) and O'Dea and Crossley (2010). Key findings from these studies are:

- Spending reported in the US CE makes up about $70 \%$ of aggregate levels. In the UK LCF, the figure is around $80 \%$. Both have worsened over time. The decline in UK coverage is particularly noticeable from the early 1990s.

- Similar trends occur for food at home. In the US, coverage fell from more than $75 \%$ in the 1980 s to around $65 \%$ by the early 2000 s. In the UK, coverage fell from more than $95 \%$ in the 1970 s to less than $90 \%$ by the early 2000 s.

We focus on food at home and off-licence alcohol expenditures in the UK National Accounts (NA) and compare them to spending reported in the LCF and, for the first time, Kantar Worldpanel data. ${ }^{11}$ We are not aware of other papers which have made similar comparisons of scanner data to national spending figures in this way. Our interest is not just in how much of total aggregate expenditure is reported in the surveys, but also in whether trends over time are similar. There are a number of reasons why we would expect food spending to be higher in NA data than survey data. NA figures include expenditures by people living in non-housing accommodation (student halls, old age homes, army barracks and so on) and spending by tourists in the UK which are not included in the surveys. NA figures are also based on UK-wide expenditures (including Northern Ireland). Since the Kantar data covers only Great Britain (excluding Northern Ireland), for consistency across surveys we also look at LCF data for Great Britain.

To make the comparisons, we need to aggregate the LCF and Kantar survey data to national totals. The LCF reports weekly household-level expenditure by commodity group and provides sampling weights for each household which gross up the data to national

\footnotetext{
${ }^{11}$ For information on data used to compile NA expenditure figures, see Office for National Statistics (2010a).
} 
figures. Thus we convert weekly expenditure figures to annual figures (multiplying by 52) and use the weights to generate national annual expenditures. In the Kantar data, sampling weights are provided for each household covering different periods of time (e.g. 4 weeks, 52 weeks). Households who fail to report expenditures consistently over that period are assigned a zero weight, with the weights of other households adjusted such that the figures gross up to national totals. We calculate total aggregated expenditures by commodity over a series of 4-week periods using the appropriate weights. These are then further aggregated into annual totals by adding up the thirteen 4-week periods that generate a 52-week 'year' which closely (though not perfectly) covers a single calendar year. ${ }^{12}$ We convert aggregated figures to weekly averages.

Figure 4.1 shows average total weekly food and drink expenditure in the NA and the survey datasets between 2002 and 2009, the period for which full-year comparisons can be made. Figure 4.2 reports year-on-year growth rates.

Figure 4.1 Gross weekly food and drink expenditures, 2002-2009

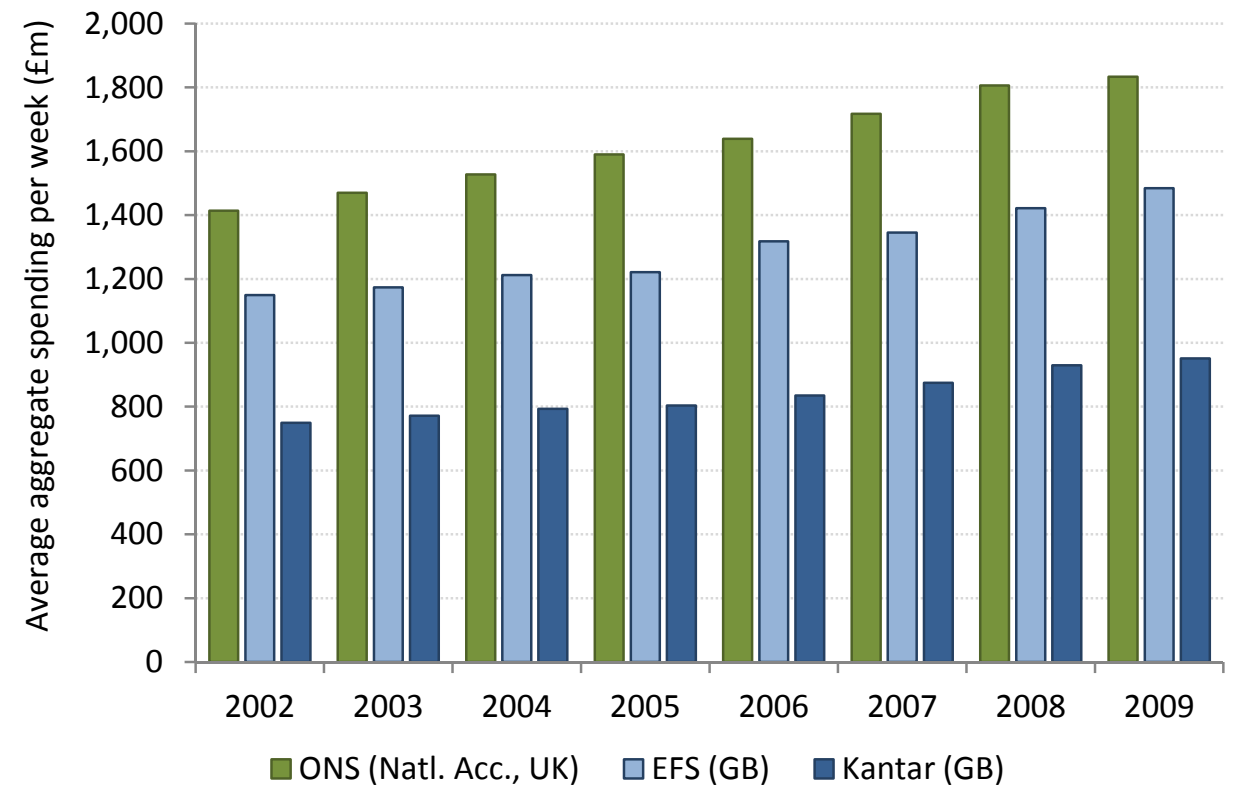

Source: Calculated from UK Office for National Statistics Data, LCF data and Kantar Worldpanel.

\footnotetext{
${ }^{12}$ For example, the period labelled 2002 in the Kantar figures covers Jan $7^{\text {th }} 2002-\operatorname{Jan} 5^{\text {th }} 2003$.
} 
Figure 4.2: Growth rates of aggregate expenditure, ONS and survey data

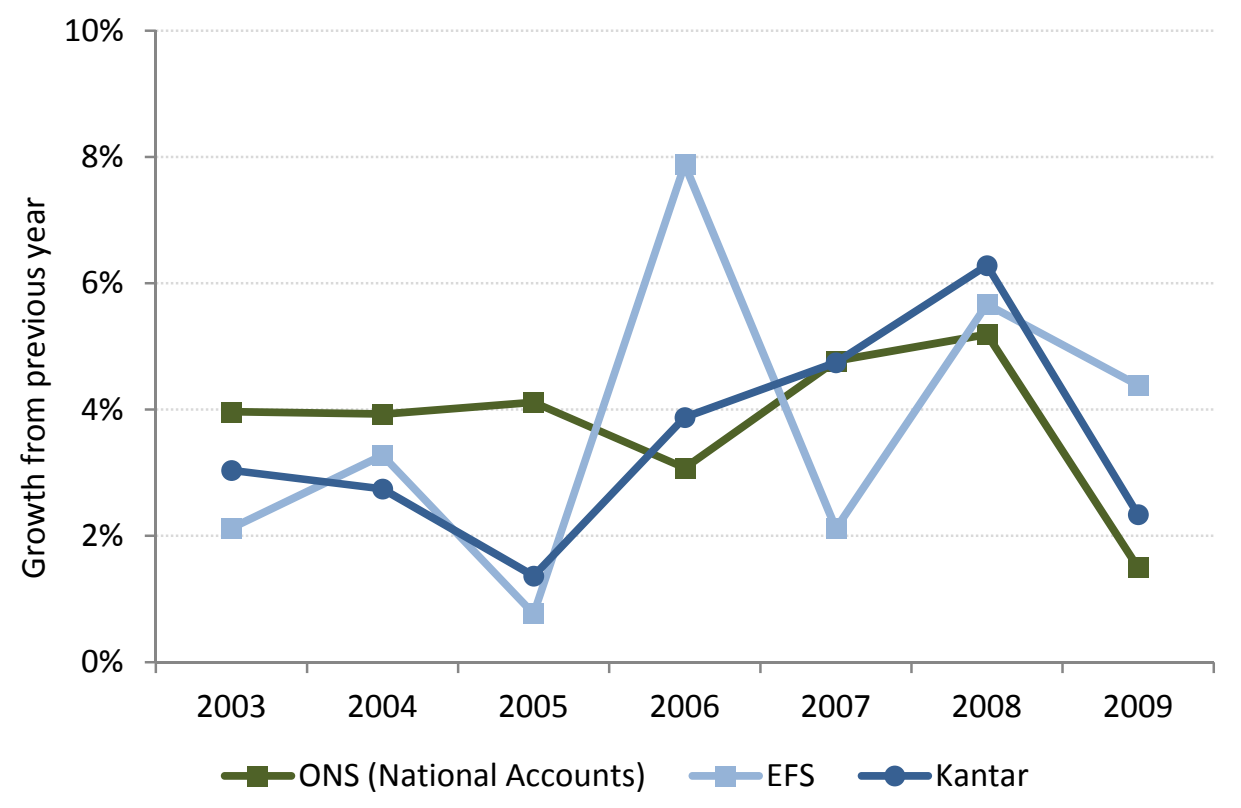

Source: Calculated from UK Office for National Statistics Data, LCF data and Kantar Worldpanel.

Levels of spending in the LCF are about 79 to $81 \%$ of those in NA data. ${ }^{13}$ Those in the Kantar data are about 51 to $53 \%$ of NA values. Looking at growth rates, there is much more volatility in the LCF. Aggregate spending on food and drink grew by around $8 \%$ between 2005 and 2006, a spike not seen in other data. The NA and Kantar figures suggest a sharp slowdown in spending in 2009, but this is not reflected in the LCF data. There is no evidence that the Kantar data perform worse than the LCF when compared to NA data. Indeed, the larger sample size in the Kantar data mitigates the volatility in growth rates observed in the LCF. Such volatility cautions against making year-on-year inferences about changes in living standards from consumption changes in the LCF.

Table 4.1 disaggregates total food expenditures in the surveys and NA into groups based on CPI commodity definitions. Figures are shown for 2002 and 2009, the start and end of our comparison period. Food items are better reported than either alcohol or nonalcoholic beverages in both survey datasets. The relative under-reporting of drinks compared to food is striking. ${ }^{14}$ Interestingly, the LCF data appear if anything relatively worse at recording non-alcoholic drinks than alcoholic drinks whilst the reverse is true in the Kantar data. Within food, spending on bread and fish appears to be particularly well captured in survey data. There appears to be some issue in how sugar and confectionery products are reported as well as 'other food'. Given what appear to be high relative reports of survey expenditure on other food and low reports of sugar and confectionery, it could be some coding issue where items that are included in the NA definition of confectionery are included in the LCF definition of other food. It is not clear what drives this, and we cannot drill down into the NA figures in more detail. In principle, the LCF expenditure codes should map directly on to the NA commodity codes since both use the

\footnotetext{
${ }^{13}$ This is not simply because of geography - the absence of Northern Ireland from the survey data is not nearly enough to account for the lower spending. In 2009, for example, we find LCF expenditures are $81 \%$ of those reported in the NA; adding Northern Ireland back in raises this to just $83 \%$.

${ }^{14}$ By 2009 only $54 \%$ of soft drink expenditure in the NA was captured in the LCF, compared to $75 \%$ of wine expenditure and $61 \%$ of beer expenditure. Much attention has been paid to the relative under-recording of alcohol in surveys but these results show the same is also true of soft drinks.
} 
COICOP (Classification of Individual Consumption by Purpose) categorisation method. Since we map the Kantar products onto LCF codes, these too should then translate directly into comparable NA commodities.

Comparing across the LCF and Kantar datasets, those commodities which are relatively well reported in one also tend to be relatively well reported in the other. The most notable differences come in alcohol where reported Kantar spending is relatively lower than reported LCF spending. Within alcohol there are differences too: for example, the LCF does comparatively badly at recording spirits purchases, capturing just $44 \%$ of NA expenditure (compared to $61 \%$ for beer and $75 \%$ for wine). In the Kantar data, it is beer that is least well recorded (29\% of NA spending). This could be due to the way the data is collected. In the LCF, each household member has an individual diary to fill out. In the Kantar data, whilst in principle each household member should record items brought home, in practice it may be that main shopping trips are well-reported whilst those carried out by secondary shoppers are less well captured. If main shoppers are mostly female and men buy more beer, this might explain this finding. 
Table 4.1: Gross expenditures by commodity in National Accounts, LCF and Kantar data, 2002 and 2009

\begin{tabular}{|c|c|c|c|c|c|c|c|c|c|c|c|c|}
\hline & \multicolumn{6}{|c|}{$£$ million / week } & \multicolumn{6}{|c|}{ Ratios } \\
\hline & \multicolumn{3}{|c|}{2002} & \multicolumn{3}{|c|}{2009} & \multicolumn{2}{|c|}{ LCF / NA } & \multicolumn{2}{|c|}{ Kantar / NA } & \multicolumn{2}{|c|}{ Kantar / LCF } \\
\hline & NA & $\mathrm{LCF}$ & Kantar & NA & $\mathrm{LCF}$ & Kantar & 2002 & 2009 & 2002 & 2009 & 2002 & 2009 \\
\hline TOTAL & $1,413.6$ & $1,149.3$ & 749.0 & $1,833.5$ & $1,484.0$ & 951.2 & $81 \%$ & $81 \%$ & $53 \%$ & $52 \%$ & $65 \%$ & $64 \%$ \\
\hline FOOD & $1,057.5$ & 922.4 & 620.9 & $1,377.3$ & $1,209.3$ & 787.5 & $87 \%$ & $88 \%$ & $59 \%$ & $57 \%$ & $67 \%$ & $65 \%$ \\
\hline Bread and cereals & 176.9 & 177.9 & 120.5 & 230.8 & 234.0 & 156.4 & $101 \%$ & $101 \%$ & $68 \%$ & $68 \%$ & $68 \%$ & $67 \%$ \\
\hline Meat & 248.3 & 227.3 & 155.2 & 315.7 & 284.1 & 182.4 & $92 \%$ & $90 \%$ & $62 \%$ & $58 \%$ & $68 \%$ & $64 \%$ \\
\hline Fish & 46.1 & 44.4 & 27.8 & 56.6 & 58.3 & 35.7 & $96 \%$ & $103 \%$ & $60 \%$ & $63 \%$ & $63 \%$ & $61 \%$ \\
\hline Milk, cheese and eggs & 145.6 & 125.6 & 84.1 & 210.0 & 180.7 & 120.2 & $86 \%$ & $86 \%$ & $58 \%$ & $57 \%$ & $67 \%$ & $67 \%$ \\
\hline Oils and fats & 24.2 & 21.1 & 15.4 & 28.7 & 28.5 & 20.7 & $87 \%$ & $99 \%$ & $64 \%$ & $72 \%$ & $73 \%$ & $73 \%$ \\
\hline Fruit & 87.2 & 74.1 & 47.8 & 125.6 & 99.4 & 59.5 & $85 \%$ & $79 \%$ & $55 \%$ & $47 \%$ & $65 \%$ & $60 \%$ \\
\hline Vegetables & 166.5 & 142.3 & 97.6 & 208.5 & 182.8 & 118.9 & $85 \%$ & $88 \%$ & $59 \%$ & $57 \%$ & $69 \%$ & $65 \%$ \\
\hline Sugar and confectionery & 134.8 & 66.3 & 43.4 & 160.9 & 80.4 & 56.4 & $49 \%$ & $50 \%$ & $32 \%$ & $35 \%$ & $66 \%$ & $70 \%$ \\
\hline Other food & 27.9 & 43.3 & 29.0 & 40.6 & 61.3 & 37.3 & $155 \%$ & $151 \%$ & $104 \%$ & $92 \%$ & $67 \%$ & $61 \%$ \\
\hline BEVERAGES & 141.7 & 86.3 & 58.8 & 183.9 & 103.1 & 71.4 & $61 \%$ & $56 \%$ & $41 \%$ & $39 \%$ & $68 \%$ & $69 \%$ \\
\hline Coffee, tea and cocoa & 35.1 & 25.7 & 18.3 & 47.3 & 29.5 & 21.4 & $73 \%$ & $62 \%$ & $52 \%$ & $45 \%$ & $71 \%$ & $73 \%$ \\
\hline Fruit juices and soft drinks & 106.6 & 60.6 & 40.4 & 136.6 & 73.7 & 50.0 & $57 \%$ & $54 \%$ & $38 \%$ & $37 \%$ & $67 \%$ & $68 \%$ \\
\hline ALCOHOL & 214.4 & 140.5 & 69.3 & 272.3 & 171.6 & 92.3 & $66 \%$ & $63 \%$ & $32 \%$ & $34 \%$ & $49 \%$ & $54 \%$ \\
\hline Spirits & 55.8 & 28.1 & 18.9 & 74.9 & 32.7 & 24.4 & $50 \%$ & $44 \%$ & $34 \%$ & $33 \%$ & $67 \%$ & $75 \%$ \\
\hline Wines, cider and perry & 103.2 & 75.8 & 34.8 & 131.1 & 98.3 & 49.0 & $74 \%$ & $75 \%$ & $34 \%$ & $37 \%$ & $46 \%$ & $50 \%$ \\
\hline Beer & 55.4 & 36.6 & 15.7 & 66.4 & 40.6 & 19.0 & $66 \%$ & $61 \%$ & $28 \%$ & $29 \%$ & $43 \%$ & $47 \%$ \\
\hline
\end{tabular}

Source: Author's calculations from ONS, LCF and Kantar Worldpanel data. Notes: NA = National Accounts, LCF = Living Costs and Food Survey. LCF and Kantar data are for Great

Britain, whilst NA data are for the UK (including Northern Ireland). LCF and Kantar data are converted to gross national annual totals using supplied household sampling weights; all data are then expressed as weekly average expenditures. 
Comparing results for 2002 and 2009 tells us where survey expenditure measures have grown more or less quickly than those in the NA. A noticeable shift occurs for oils and fats, where spending growth was much faster in the both surveys than the NA. This is driven by a sharp fall of around 15\% in spending between 2008 and 2009 in the NA, with much smaller declines in the surveys. There is also a relative decline in both surveys for fruit spending. Again, this is driven mostly by a single year: fruit spending grew by more than $16 \%$ in 2005 in the NA data, but only by around $7 \%$ in the two surveys. Detailed figures for spending ratios and growth rates in each year for each commodity are available on request, but broadly the conclusion from earlier that (a) spending growth is more volatile in the LCF than either the NA or Kantar data sources and that (b) there is no clear 'winner' between the LCF and Kantar as to which tracks growth rates observed in the NA holds across commodities as well.

\subsection{Comparing scanner and budget survey expenditure data}

We now make detailed comparisons between the survey measures of spending from Kantar and the LCF. This analysis is useful not only as a way to compare, contrast and validate the different expenditure surveys but also to inform us about how useful existing scanner data might be for imputing detailed expenditures into budget survey data (see Section 5). If we find that expenditure patterns are very different in the Worldpanel and LCF, we might be less confident about using scanner data to try and predict detailed expenditures in the survey data given high-level information on total outlays.

When making cross-dataset comparisons, it is important to bear in mind that they are collected in very different ways. The LCF is recorded over two weeks based on diaries kept by each household member. Respondents are contacted at least once during the two week period to check for any problems filling in the diary, and a thorough check is made of the diaries at the end of the period to ensure they have been properly completed (Ayres et al, 2010). In the Kantar data, each household can participate for as long as they wish. They are contacted every nine months or so to check that demographic information is up to date, but in general attempts to ensure good compliance are limited. Thus if we want to compare average spending levels and patterns in the LCF to those in the Kantar data, the crucial issue is what sample of households we select from the Kantar data, over what period of time we choose to observe them and how we deal with seeming periods of non-compliance. Leicester and Oldfield (2009), for example, look at average weekly expenditures in the Kantar data amongst households who report spending in at least four separate weeks (not necessarily consecutive) in a given year. They include only those weeks in which some spending is observed. On this basis, they find that average total food and drink expenditures were about $25 \%$ lower in the Kantar data than in the LCF data in 2005 , once observable demographic differences in the samples were taken into account. ${ }^{15}$

\section{Sample selection}

Our main comparisons between LCF and Kantar data cover calendar year 2009.16 In the LCF, we exclude all households in Northern Ireland to ensure the geographical coverage of the two datasets is comparable. This gives a sample size of 5,220 households.

\footnotetext{
${ }^{15}$ They find a smaller gap of around $16 \%$ when comparing the first two full weeks of expenditure for households newly signed up to the Kantar data (again excluding cases where either week includes zero expenditure). This could reflect the 'fatigue' issue mentioned above which sees recorded spending drop off slightly with the length of participation.

${ }^{16}$ As in the comparison to National Accounts aggregates above, we use a 52 -week Kantar period which does not quite overlap with the calendar year, running from $29^{\text {th }}$ December 2008 until $27^{\text {th }}$ December 2009.
} 
In the Kantar data, a total of 26,655 separate households are observed making at least one purchase in 2009. We look first at households who, according to the dates at which they signed up to and dropped out of the survey, were active during the whole period. This gives a 'non-dropout' sample of 21,093 households (79.1\% of the full sample). As an additional selection, we also condition on households who have no reporting gap (period during which no food and drink expenditures at all are recorded) exceeding 6 weeks. ${ }^{17}$ While this threshold is somewhat arbitrary, the intention is to try and exclude households who do not appear to be fully compliant over the whole year. Shorter periods of nonreporting might be reconciled as holiday periods, for example, but it seems somewhat unlikely that many households would legitimately purchase no food items for that long. This 'regular reporter' sample includes 15,781 households. Leicester (2012) shows that households excluded by this sample selection are significantly more likely to be in London, be headed by someone aged under 40 or over 60 , be headed by a female, to have larger numbers of adults or children, and to have missing demographic information either on income, employment status or the number of cars. Households who are not required to report non-barcoded items are significantly more likely to be part of the 'regular reporter' sample, which suggests that the reduced respondent burden may encourage households to report spending consistently. Income and employment status have no independent effects on the likelihood of selection into this sample. The fact that our preferred 'regular reporter' sample is clearly a non-random set of all Kantar households should be borne in mind when comparing raw expenditures. Later in this section, we condition on observable demographics across the datasets to see how far they can explain spending differences. ${ }^{18}$

\section{Comparisons of average expenditure and budget shares}

Table 4.2 shows average expenditures per week, by CPI commodity, from the LCF and Kantar data during 2009. To strip out the effects of household composition, expenditures are equivalised using the before housing costs modified OECD equivalence scale. ${ }^{19} \mathrm{We}$ look at a number of different Kantar samples. First, we take the 'no dropout' sample and pick a random consecutive two week period (matching the LCF diary period) over which to observe expenditures. This approach assumes that weeks in which households record no food spending are accurate reflections of true purchasing behaviour. We then make the additional selection described above and drop households with long reporting gaps. Within this sample, we look at average weekly spending when we choose observation periods of different length. ${ }^{20}$ Finally, for each Kantar household in this sample, we select the longest consecutive set of weeks containing any recorded expenditure at all. This in effect assumes that all weeks in which zero spending is recorded are inaccurate. The mean duration of observation in this sample is 25.1 weeks.

\footnotetext{
${ }^{17}$ We do not consider whether or not households buy non-food items during this period.

${ }^{18}$ In the Kantar data, we observe household spending over a full year period. We have demographic data once a year for each household that are updated roughly each November. For the 2009 sample, then, the demographics refer to November 2008 values.

${ }^{19}$ See Appendix A of Jin et al (2011) for details of equivalence scales.

${ }^{20}$ Results over 2 and 52 weeks are shown; figures for periods of 4, 12 and 26 weeks essentially show the same results and are available on request.
} 
Table 4.2. Weekly average equivalised expenditure levels by CPI commodity group, LCF and Kantar, 2009

\begin{tabular}{|c|c|c|c|c|c|c|c|c|c|c|}
\hline & \multirow{3}{*}{\multicolumn{2}{|c|}{$\frac{\text { LCFS }}{2 \text { weeks }}$}} & \multicolumn{8}{|c|}{ Kantar } \\
\hline & & & \multirow{2}{*}{\multicolumn{2}{|c|}{$\frac{\text { Non-dropouts }}{2 \text { weeks }}$}} & \multicolumn{6}{|c|}{ Regular reporters } \\
\hline & & & & & \multicolumn{2}{|c|}{2 weeks } & \multicolumn{2}{|c|}{52 weeks } & \multicolumn{2}{|c|}{ Longest continuous } \\
\hline & Mean & SD & Mean & SD & Mean & SD & Mean & SD & Mean & SD \\
\hline Bread and cereals & 8.51 & 5.20 & 5.65 & 4.63 & 6.34 & 4.54 & 6.36 & 2.98 & 7.17 & 3.24 \\
\hline Meat & 10.65 & 8.73 & 6.78 & 6.86 & 7.64 & 6.94 & 7.60 & 4.64 & 8.54 & 5.17 \\
\hline Fish & 2.25 & 3.43 & 1.33 & 2.20 & 1.50 & 2.28 & 1.51 & 1.40 & 1.70 & 1.65 \\
\hline Milk, cheese and eggs & 6.75 & 4.48 & 4.38 & 3.71 & 4.96 & 3.67 & 4.97 & 2.55 & 5.61 & 2.77 \\
\hline Oils and fats & 1.08 & 1.23 & 0.78 & 1.07 & 0.88 & 1.11 & 0.88 & 0.61 & 0.98 & 0.71 \\
\hline Fruit & 3.81 & 3.94 & 2.19 & 2.91 & 2.48 & 3.04 & 2.48 & 2.25 & 2.83 & 2.57 \\
\hline Vegetables & 6.81 & 4.87 & 4.32 & 3.95 & 4.86 & 3.94 & 4.88 & 2.70 & 5.56 & 3.08 \\
\hline Sugars, confectionery & 3.01 & 3.32 & 2.06 & 2.90 & 2.34 & 3.03 & 2.34 & 1.76 & 2.61 & 2.04 \\
\hline Other food & 2.23 & 3.46 & 1.35 & 1.65 & 1.50 & 1.67 & 1.51 & 0.91 & 1.69 & 1.11 \\
\hline FOOD & 45.10 & 24.03 & 28.82 & 20.82 & 32.50 & 19.87 & 32.53 & 13.56 & 36.70 & 14.32 \\
\hline Coffee, tea and cocoa & 1.15 & 1.68 & 0.82 & 1.51 & 0.94 & 1.58 & 0.94 & 0.85 & 1.05 & 0.99 \\
\hline Mineral water, soft drinks & 2.58 & 2.77 & 1.78 & 2.35 & 1.98 & 2.40 & 1.98 & 1.67 & 2.24 & 1.92 \\
\hline BEVERAGES & 3.73 & 3.31 & 2.60 & 2.95 & 2.92 & 2.99 & 2.92 & 1.92 & 3.29 & 2.19 \\
\hline Spirits & 1.36 & 4.69 & 0.94 & 4.05 & 1.06 & 4.32 & 1.09 & 3.07 & 1.17 & 3.48 \\
\hline Wine & 3.81 & 10.44 & 1.90 & 5.32 & 2.17 & 5.67 & 2.17 & 4.17 & 2.42 & 4.82 \\
\hline Beer & 1.45 & 3.89 & 0.77 & 2.97 & 0.86 & 3.19 & 0.85 & 2.04 & 0.96 & 2.43 \\
\hline ALCOHOL & 6.63 & 13.05 & 3.61 & 8.40 & 4.10 & 8.88 & 4.11 & 6.52 & 4.56 & 7.44 \\
\hline TOTAL SPENDING & 55.46 & 31.28 & 35.03 & 26.03 & 39.52 & 25.03 & 39.56 & 17.18 & 44.56 & 18.29 \\
\hline \# households & \multicolumn{2}{|c|}{5,220} & \multicolumn{2}{|c|}{21,093} & \multicolumn{2}{|c|}{15,781} & \multicolumn{2}{|c|}{15,781} & \multicolumn{2}{|c|}{15,781} \\
\hline$\%$ zero weeks & \multicolumn{2}{|c|}{$2.7 \%$} & \multicolumn{2}{|c|}{$21.7 \%$} & \multicolumn{2}{|c|}{$13.2 \%$} & \multicolumn{2}{|c|}{$13.2 \%$} & \multicolumn{2}{|c|}{$0.0 \%$} \\
\hline Avg non-zero weeks/hh & \multicolumn{2}{|c|}{1.95} & \multicolumn{2}{|c|}{1.57} & \multicolumn{2}{|c|}{1.74} & \multicolumn{2}{|c|}{45.13} & \multicolumn{2}{|c|}{25.10} \\
\hline
\end{tabular}

Source: Author's calculations from 2009 Kantar Worldpanel and LCF 2009. Expenditures are equivalised using the before housing costs modified OECD scale. 
Average household weekly equivalised food and drink expenditures in 2009 were $£ 55.46$ in the LCF. Expenditures in the Kantar data were lower for all samples. For the 'no dropout' sample observed over two weeks, expenditures were $£ 35.03$, almost $37 \%$ below the LCF figure. Excluding those with long gaps in reporting, average spending rises to $£ 39.52$ (29\% below the LCF figure) when households are observed over a random two weeks or $£ 39.56$ observed over the full 52 weeks. It is striking how little difference there is in average expenditures when households are observed for a full year rather than a single two week period, though the standard deviation of expenditures falls markedly. We return to this issue shortly. Finally, once we ignore zero spending weeks altogether, average spending rises to $£ 44.56$, a gap of just under $20 \%$ compared to LCF levels.

These figures make clear that the treatment of weeks in which zero expenditure is reported is hugely important. Around half of the gap between Kantar and LCF expenditures is eliminated once we strip these weeks out. The greater propensity for zero spending weeks in the Kantar data than the LCF is striking and should be a priority for further analysis. It could reflect households who have effectively attrited but not formally dropped out. However, many households have reporting behaviour which is not consistent with this - for example, they report nothing for a few weeks then start scanning again. Understanding what drives this in scanner data would be useful.

Table 4.3 shows Kantar expenditures relative to LCF expenditures for various sample definitions, and Table 4.4 shows the expenditures in terms of budget shares. Even if average expenditures are lower in the scanner data, if the extent of 'under-reporting' is quite consistent such that the patterns of expenditure are similar, this acts as a useful validation (of both data sources) and gives us more confidence in trying to use scanner data as a means to impute detailed budget shares from aggregate expenditure data.

Table 4.3. Kantar as a proportion of LCF expenditure, 2009

\begin{tabular}{|c|c|c|c|c|}
\hline & \multirow{2}{*}{$\frac{\text { All }}{2 \text { weeks }}$} & \multicolumn{3}{|c|}{ Regular reporters } \\
\hline & & 2 weeks & 52 weeks & Longest \\
\hline Bread and cereals & $66.4 \%$ & $74.5 \%$ & $74.7 \%$ & $84.3 \%$ \\
\hline Meat & $63.7 \%$ & $71.7 \%$ & $71.4 \%$ & $80.2 \%$ \\
\hline Fish & $59.1 \%$ & $66.7 \%$ & $67.1 \%$ & $75.6 \%$ \\
\hline Milk, cheese and eggs & $64.9 \%$ & $73.5 \%$ & $73.6 \%$ & $83.1 \%$ \\
\hline Oils and fats & $72.2 \%$ & $81.5 \%$ & $81.5 \%$ & $90.7 \%$ \\
\hline Fruit & $57.5 \%$ & $65.1 \%$ & $65.1 \%$ & $74.3 \%$ \\
\hline Vegetables & $63.4 \%$ & $71.4 \%$ & $71.7 \%$ & $81.6 \%$ \\
\hline Sugars, confectionery & $68.4 \%$ & $77.7 \%$ & $77.7 \%$ & $86.7 \%$ \\
\hline Other food & $60.5 \%$ & $67.3 \%$ & $67.7 \%$ & $75.8 \%$ \\
\hline FOOD & $63.9 \%$ & $72.1 \%$ & $72.1 \%$ & $81.4 \%$ \\
\hline Coffee, tea and cocoa & $71.3 \%$ & $81.7 \%$ & $81.7 \%$ & $91.3 \%$ \\
\hline Mineral water, soft drinks & $69.0 \%$ & $76.7 \%$ & $76.7 \%$ & $86.8 \%$ \\
\hline BEVERAGES & $69.7 \%$ & $78.3 \%$ & $78.3 \%$ & $88.2 \%$ \\
\hline Spirits & $69.1 \%$ & $77.9 \%$ & $80.1 \%$ & $86.0 \%$ \\
\hline Wine & $49.9 \%$ & $57.0 \%$ & $57.0 \%$ & $63.5 \%$ \\
\hline Beer & $53.1 \%$ & $59.3 \%$ & $58.6 \%$ & $66.2 \%$ \\
\hline ALCOHOL & $54.4 \%$ & $61.8 \%$ & $62.0 \%$ & $68.8 \%$ \\
\hline TOTAL SPENDING & $63.2 \%$ & $71.3 \%$ & $71.3 \%$ & $80.3 \%$ \\
\hline
\end{tabular}


Source: Author's calculations from 2009 Kantar Worldpanel and LCF 2009. Expenditures are equivalised using the before housing costs modified OECD scale.

From Table 4.3, several features emerge. The average proportion of LCF expenditures reported in the Kantar data rises for all commodities as we remove the impact of zero spending weeks. Once again, observing households for 2 weeks or 52 weeks makes little difference to the average proportion. Using the 'longest uninterrupted' measure of Kantar spending (rightmost column of Table 4.3), relative to LCF spending, Kantar expenditure levels match up most closely for non-alcoholic beverages and least closely for alcohol. Food spending is somewhere between. There are differences across disaggregate commodities: for example, the Kantar data picks up about $75 \%$ as much spending on average for fish, fruit and other foods than the LCF, but about $90 \%$ of the expenditure on oils and fats, and coffee and tea. Differences across alcohol types are particularly clear.

Expressed as shares of the total food and drink budget, Table 4.4 makes it clear that the particular sample selected from the Kantar data makes very little difference to the pattern of expenditure observed. Comparing LCF budget shares to those from the uninterrupted Kantar sample also reveals relatively small differences. For any single commodity, the largest difference in budget share is for wine, which makes up on average $5.4 \%$ of food and drink spending in the Kantar data but $6.9 \%$ of spending in the LCF. In the opposite direction, bread and cereals make up $16.1 \%$ of total Kantar food and drink spending compared to $15.3 \%$ of LCF spending.

Table 4.4. Food and drink budget shares, by survey, 2009

\begin{tabular}{l|c|c|c|c|c}
\hline \multirow{2}{*}{} & LCFS & \multicolumn{4}{|c}{ Kantar } \\
\cline { 2 - 6 } & \multirow{2}{*}{2 weeks } & All & \multicolumn{3}{|c}{ Regular reporters } \\
\cline { 3 - 6 } & & 2 weeks & 2 weeks & 52 weeks & Longest \\
\hline Bread and cereals & $15.3 \%$ & $16.1 \%$ & $16.0 \%$ & $16.1 \%$ & $16.1 \%$ \\
Meat & $19.2 \%$ & $19.4 \%$ & $19.3 \%$ & $19.2 \%$ & $19.2 \%$ \\
Fish & $4.1 \%$ & $3.8 \%$ & $3.8 \%$ & $3.8 \%$ & $3.8 \%$ \\
Milk, cheese and eggs & $12.2 \%$ & $12.5 \%$ & $12.6 \%$ & $12.6 \%$ & $12.6 \%$ \\
Oils and fats & $1.9 \%$ & $2.2 \%$ & $2.2 \%$ & $2.2 \%$ & $2.2 \%$ \\
Fruit & $6.9 \%$ & $6.3 \%$ & $6.3 \%$ & $6.3 \%$ & $6.4 \%$ \\
Vegetables & $12.3 \%$ & $12.3 \%$ & $12.3 \%$ & $12.3 \%$ & $12.5 \%$ \\
Sugars, confectionery & $5.4 \%$ & $5.9 \%$ & $5.9 \%$ & $5.9 \%$ & $5.9 \%$ \\
Other food & $4.0 \%$ & $3.9 \%$ & $3.8 \%$ & $3.8 \%$ & $3.8 \%$ \\
& $81.3 \%$ & $82.3 \%$ & $82.2 \%$ & $82.2 \%$ & $82.4 \%$ \\
\hline Coffee, tea and cocoa & $2.1 \%$ & $2.3 \%$ & $2.4 \%$ & $2.4 \%$ & $2.4 \%$ \\
Mineral water, soft drinks & $4.7 \%$ & $5.1 \%$ & $5.0 \%$ & $5.0 \%$ & $5.0 \%$ \\
& $6.7 \%$ & $7.4 \%$ & $7.4 \%$ & $7.4 \%$ & $7.4 \%$ \\
\hline Spirits BEVRAGES & $2.5 \%$ & $2.7 \%$ & $2.7 \%$ & $2.8 \%$ & $2.6 \%$ \\
Wine & $6.9 \%$ & $5.4 \%$ & $5.5 \%$ & $5.5 \%$ & $5.4 \%$ \\
Beer & $2.6 \%$ & $2.2 \%$ & $2.2 \%$ & $2.1 \%$ & $2.2 \%$ \\
& $12.0 \%$ & $10.3 \%$ & $10.4 \%$ & $10.4 \%$ & $10.2 \%$ \\
\hline
\end{tabular}

Source: Author's calculations from 2009 Kantar Worldpanel and LCF 2009.

These results are for 2009, but figures from earlier years are not very different. Figure 4.3 shows average equivalised weekly expenditures in the Kantar data (based on the uninterrupted sample definition) as a proportion of LCF values each year between 2002 
and 2009. There is a small increase over time. In 2002, Kantar households reported $78.5 \%$ as much spending as LCF households on average. This rose to $80.3 \%$ by 2009 .

\section{Figure 4.3. Average Kantar expenditures as a proportion of LCF, by year and broad commodity aggregate, 2002-2009}

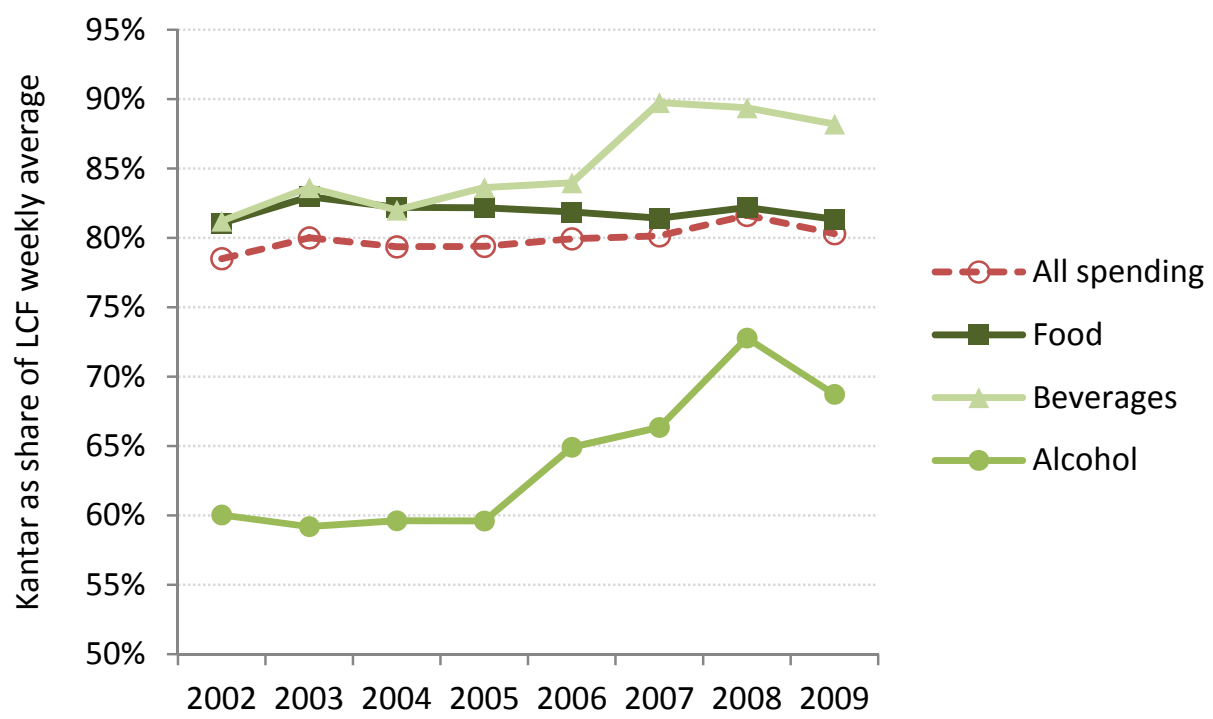

Source: Author's calculations from Kantar Worldpanel and LCF data. Note: Kantar figures relate to "longest uninterrupted" period of Kantar reporting amongst households that are active across the full calendar year and have no single reporting gap in excess of 6 weeks.

More noticeable is what appears to be a step increase between 2006 and 2007 for beverages, from about $84 \%$ to $90 \%$, and a longer term upward trend for alcohol beginning in 2006 (though stalling somewhat in 2009). This may be related to the introduction of a new scanner technology for some Kantar households in 2006, who were no longer required to scan non-barcoded items. If this made compliance costs lower it may have increased reporting of barcoded items - likely to cover almost all spending on alcohol and non-alcoholic drinks - at the cost of reducing reporting of some other categories of spending. ${ }^{21}$ More detailed analysis lends some support to this: between 2005 and 2009, for example, weekly average spending on meat in the Kantar data fell from $82.5 \%$ to $80.2 \%$ of the LCF average; for dairy products (including cheese) from $85.0 \%$ to $83.1 \%$; for fruit from $77.1 \%$ to $74.3 \%$ and vegetables from $83.7 \%$ to $81.6 \%$. Table 4.5 uses the 2009 data and makes a direct comparison between households who report non-barcoded products and those who do not. We focus on the longest uninterrupted spending period. Households who do not record non-barcoded items spend on average $£ 1.65$ per week more than those who do, a statistically significant difference. The largest effects are for beer (28\% higher spending), soft drinks (22\%), other food (14\%) and wine (13\%). Spending is lower in only two categories: fruit $(22 \%$ lower) and vegetables (3\%). This leads to quite different expenditure patterns across the groups. We explore below the extent to which these differences might also be attributed to demographic differences between the groups as well as the technology they use.

\footnotetext{
${ }^{21}$ This hypothesis does not really explain what appears to be quite a sustained improvement in alcohol reporting, at least between 2005 and 2008, however.
} 
Table 4.5. Weekly expenditure comparisons, LCF and Kantar 'uninterrupted' sample 2009, by reporting of non-barcoded items

\begin{tabular}{|c|c|c|c|c|c|c|c|c|c|c|c|}
\hline & \multicolumn{4}{|c|}{ Average weekly spending } & \multicolumn{4}{|c|}{ Budget shares } & \multicolumn{3}{|c|}{ Kantar / LCFS } \\
\hline & \multirow{2}{*}{ LCFS } & \multicolumn{3}{|c|}{ Kantar (longest continuous) } & \multirow{2}{*}{ LCFS } & \multicolumn{3}{|c|}{ Kantar (longest continuous) } & \multirow{2}{*}{ All } & \multirow{2}{*}{ Yes RW } & \multirow{2}{*}{ No RW } \\
\hline & & All & Yes RW & No RW & & All & Yes RW & No RW & & & \\
\hline Bread and cereals & 8.51 & 7.17 & 6.99 & 7.44 & $15.3 \%$ & $16.1 \%$ & $15.9 \%$ & $16.3 \%$ & $84.3 \%$ & $82.1 \%$ & $87.4 \%$ \\
\hline Meat & 10.65 & 8.54 & 8.42 & 8.73 & $19.2 \%$ & $19.2 \%$ & $19.2 \%$ & $19.2 \%$ & $80.2 \%$ & $79.1 \%$ & $82.0 \%$ \\
\hline Fish & 2.25 & 1.70 & 1.69 & 1.71 & $4.1 \%$ & $3.8 \%$ & $3.8 \%$ & $3.8 \%$ & $75.6 \%$ & $75.1 \%$ & $76.0 \%$ \\
\hline Milk, cheese and eggs & 6.75 & 5.61 & 5.55 & 5.71 & $12.2 \%$ & $12.6 \%$ & $12.6 \%$ & $12.5 \%$ & $83.1 \%$ & $82.2 \%$ & $84.6 \%$ \\
\hline Oils and fats & 1.08 & 0.98 & 0.98 & 0.99 & $1.9 \%$ & $2.2 \%$ & $2.2 \%$ & $2.2 \%$ & $90.7 \%$ & $90.7 \%$ & $91.7 \%$ \\
\hline Fruit & 3.81 & 2.83 & 3.10 & 2.41 & $6.9 \%$ & $6.4 \%$ & $7.1 \%$ & $5.3 \%$ & $74.3 \%$ & $81.4 \%$ & $63.3 \%$ \\
\hline Vegetables & 6.81 & 5.56 & 5.63 & 5.45 & $12.3 \%$ & $12.5 \%$ & $12.8 \%$ & $12.0 \%$ & $81.6 \%$ & $82.7 \%$ & $80.0 \%$ \\
\hline Sugars, confectionery & 3.01 & 2.61 & 2.53 & 2.73 & $5.4 \%$ & $5.9 \%$ & $5.8 \%$ & $6.0 \%$ & $86.7 \%$ & $84.1 \%$ & $90.7 \%$ \\
\hline Other food & 2.23 & 1.69 & 1.60 & 1.83 & $4.0 \%$ & $3.8 \%$ & $3.6 \%$ & $4.0 \%$ & $75.8 \%$ & $71.7 \%$ & $82.1 \%$ \\
\hline FOOD & 45.10 & 36.70 & 36.50 & 37.01 & $81.3 \%$ & $82.4 \%$ & $83.1 \%$ & $81.3 \%$ & $81.4 \%$ & $80.9 \%$ & $82.1 \%$ \\
\hline Coffee, tea and cocoa & 1.15 & 1.05 & 1.01 & 1.11 & $2.1 \%$ & $2.4 \%$ & $2.3 \%$ & $2.4 \%$ & $91.3 \%$ & $87.8 \%$ & $96.5 \%$ \\
\hline Mineral water, soft drinks & 2.58 & 2.24 & 2.06 & 2.52 & $4.7 \%$ & $5.0 \%$ & $4.7 \%$ & $5.5 \%$ & $86.8 \%$ & $79.8 \%$ & $97.7 \%$ \\
\hline BEVERAGES & 3.73 & 3.29 & 3.07 & 3.63 & $6.7 \%$ & $7.4 \%$ & $7.0 \%$ & $8.0 \%$ & $88.2 \%$ & $82.3 \%$ & $97.3 \%$ \\
\hline Spirits & 1.36 & 1.17 & 1.17 & 1.18 & $2.5 \%$ & $2.6 \%$ & $2.7 \%$ & $2.6 \%$ & $86.0 \%$ & $86.0 \%$ & $86.8 \%$ \\
\hline Wine & 3.81 & 2.42 & 2.30 & 2.61 & $6.9 \%$ & $5.4 \%$ & $5.2 \%$ & $5.7 \%$ & $63.5 \%$ & $60.4 \%$ & $68.5 \%$ \\
\hline Beer & 1.45 & 0.96 & 0.87 & 1.11 & $2.6 \%$ & $2.2 \%$ & $2.0 \%$ & $2.4 \%$ & $66.2 \%$ & $60.0 \%$ & $76.6 \%$ \\
\hline ALCOHOL & 6.63 & 4.56 & 4.33 & 4.90 & $12.0 \%$ & $10.2 \%$ & $9.9 \%$ & $10.8 \%$ & $68.8 \%$ & $65.3 \%$ & $73.9 \%$ \\
\hline TOTAL SPENDING & 55.46 & 44.56 & 43.90 & 45.55 & & & & & $80.3 \%$ & $79.2 \%$ & $82.1 \%$ \\
\hline \# households & 5,220 & 15,781 & 9,508 & 6,273 & & & & & & & \\
\hline Avg non-zero weeks/hh & 1.95 & 25.10 & 25.06 & 25.14 & & & & & & & \\
\hline
\end{tabular}

Source: Author's calculations from 2009 Kantar Worldpanel and LCF 2009. Expenditures are equivalised using the before housing costs modified OECD scale. "Yes RW" are households who report random-weight (non-barcoded) products; "No RW" are households who do not. 
One way to illustrate the economic significance - or otherwise - of differences in spending patterns across data sources is to ask what food inflation rates would have looked like had CPI weights for different food groups been drawn directly from the LCF or Kantar surveys, rather than based (as now) on the National Accounts aggregates. Figure 4.4 shows the 2009 food budget shares based on Kantar data (using the longest uninterrupted sample for all households), LCF data and from the CPI expenditure weights. ${ }^{22}$ Note we look only at food (a higher level CPI aggregate) and exclude drinks. The differences between LCF and Kantar data are small: the Kantar basket more heavily weights bread, dairy, fats and confectionery whilst the LCF basket more heavily weights fruit, fish and other food. There are larger differences between the weights based on survey data and those from the CPI basket. Weights for bread, meat, fairy, fats and other food are lower in the CPI than either of the survey baskets, whilst weights for confectionery and fruit are higher. The much lower spending on other food in the CPI accords with the much higher expenditure on other foods observed in the surveys than the National Accounts aggregates in Section 4.1 above.

Figure 4.4. Food commodity weights, LCF, Kantar and CPI, 2009

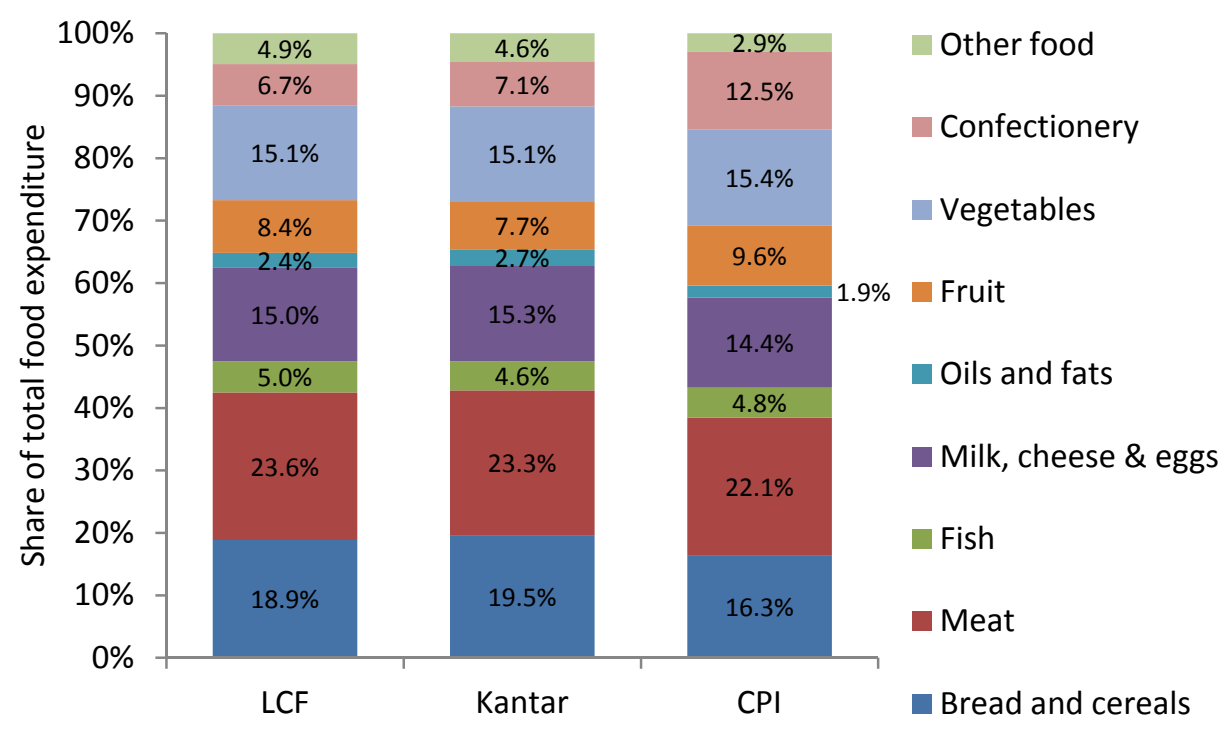

Source: Author's calculations based on 2009 Kantar Worldpanel, LCF and ONS data.

Figure 4.5 shows the different inflation rates for food that result from applying survey- and year-specific commodity weights. The left-hand panel gives the results as index numbers between January 2002 and December 2009; the right-hand panel as annual inflation rates starting in January 2003. ${ }^{23}$ Overall, the effect of re-weighting the food CPI using LCF and Kantar-specific commodity weights is small. Over the whole period, the food CPI rose by $29.6 \%$ whereas an index based on LCF weights rose by $28.1 \%$ and one based on Kantar weights rose by $28.6 \%$. The average annual food inflation rate between 2003 and 2009 was 3.8\% based on CPI weights, and $3.7 \%$ based on weights from both surveys. The largest absolute gap for any single month between the CPI-weighted inflation rate and the LCF-weighted rate was $0.5 \%$. The largest gap comparing CPI-weighted and Kantar-weighted inflation rates was $0.7 \%$. The largest gap comparing LCF-weighted and Kantar-weighted inflation rates was just $0.3 \%$.

\footnotetext{
${ }^{22}$ Note that CPI weights are based on National Accounts expenditure aggregates which are in turn based on slightly out-dated expenditure data from the LCF. For example, 2010 weights in the CPI are heavily influenced by LCF data from 2008 and 2009 . Our estimates based on LCF and Kantar data use contemporaneous data, e.g. the 2009 weights are based on 2009 data.

${ }^{23}$ Figures were calculated by calculating within-year price indices for each food sub-group based at 100 in January and using the different weights to calculate a within-year food index. These indices are then 'chained' to give a series over the whole time period. See Section 2.5 of Office for National Statistics (2010b) for more on chaining.
} 
Figure 4.5: CPI food price indices and inflation rates, based on CPI, LCF and Kantar expenditure weights, 2002-2009

(a) Price Index (January 2002 = 100)

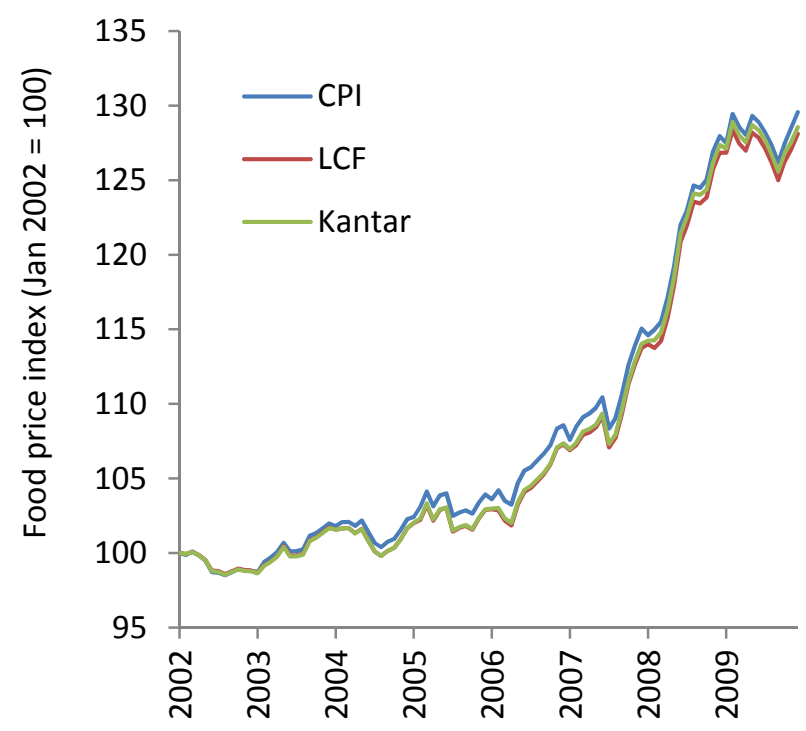

(b) Annual inflation rate

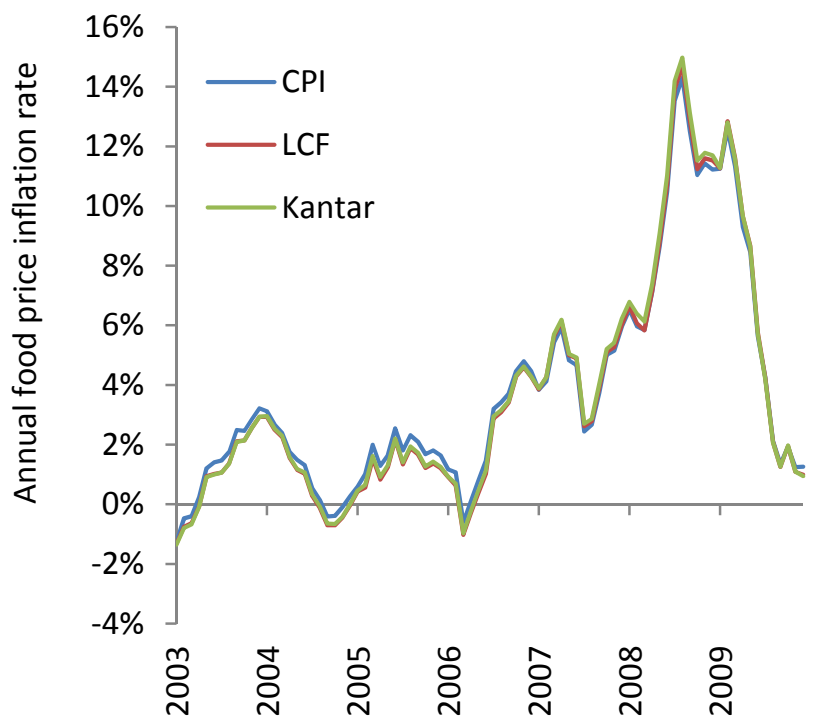

Source: Author's calculations based on 2002-2009 Kantar Worldpanel, LCF and ONS data.

\section{Distributions of spending and budget shares}

The comparisons so far have focused on average spending levels and budget shares. However, looking at their distribution across households is informative. It helps to understand what might be driving differences in the averages. Further, even if (as we saw above) changing the period over which we observe Kantar households makes little difference to the average budget share or spending level, it may still affect the distribution. For issues like poverty and inequality it is the distribution which matters. Figure 4.6 shows a density plot of the distribution of average equivalised weekly food and drink spending in 2009 for the LCF, and 'regular reporter' Kantar households observed over 2 weeks, 52 weeks and for the longest uninterrupted number of weeks.

Figure 4.6. Distribution of equivalised weekly food \& drink expenditures, 2009

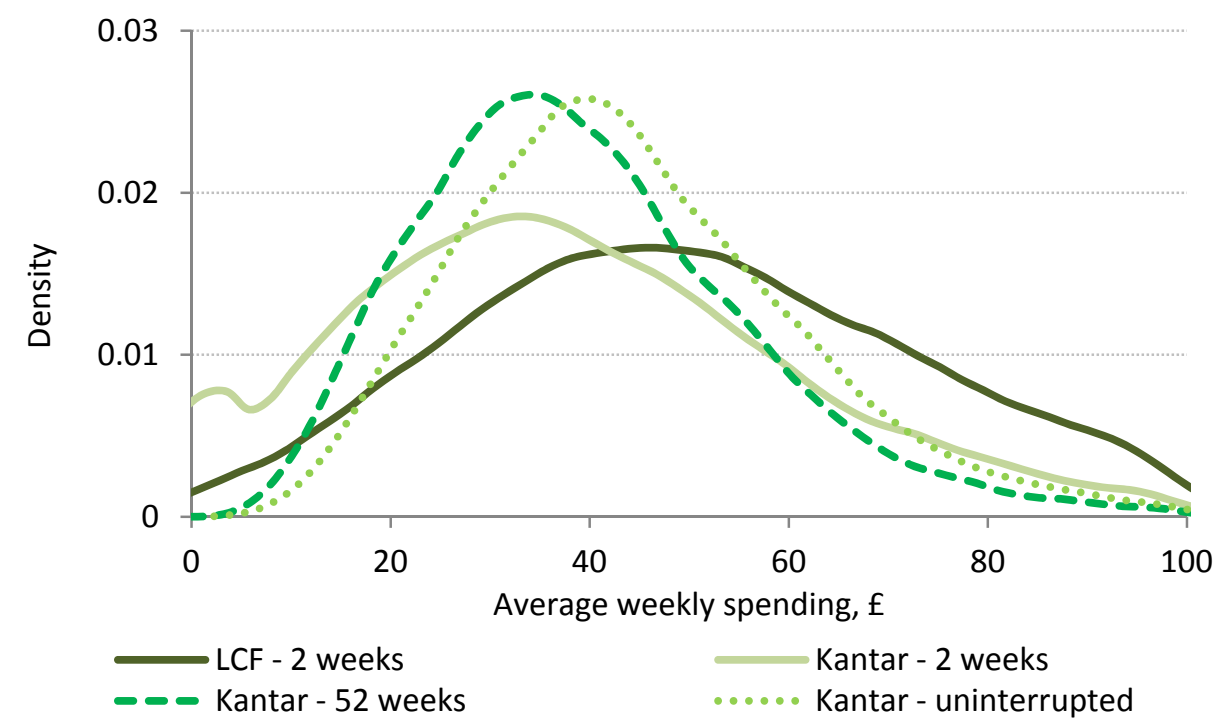

Source: Author's calculations based on 2009 Kantar Worldpanel and LCF data. 
The distribution for LCF households is relatively smooth over the range of spending shown. However, when we observe Kantar households for just two weeks, there is a bulge in the distribution at zero, reflecting the high prevalence of zero expenditure weeks. Observed over longer periods, the distribution of expenditures in the Kantar data become more smoothly distributed though clearly skewed somewhat more towards lower expenditures than the LCF figures. There are notably far fewer high-spending households in the Kantar data than the LCF.

Even more interesting is the impact of observation period on commodity-level budget shares. One problem with observing expenditure over a short horizon like two weeks is that households may purchase and consume some goods relatively infrequently. To take a stylised example: imagine that all households shop once a week and consume one can of beer per week. Beer is only sold in 4-packs which sell for $£ 5$. Households therefore spend $£ 5$ on beer once every four weeks, and average weekly beer consumption is $£ 1.25$. If we took a random two week period, we would observe half of households buying beer (consuming $£ 2.50$ per week) and half of households buying no beer (consuming $£ 0$ per week). The average value of consumption across all households would be right, but the distribution would be wrong. Given the wide availability of freezer and refrigerator space and the ability to store some food and drink items (like canned goods) for a long time, there is also scope for households to engage in stockpiling: buying goods when they are cheap (perhaps on a temporary special offer) for consumption over a long period. The longer the horizon over which we can observe spending patterns, therefore, the more accurate a record of true consumption that data is likely to represent.

Leicester (2012) takes the regular reporter Kantar sample and shows that, observed over a full year, almost all households are observed to purchase from all CPI commodity groups whereas observed over two weeks, large numbers report zero expenditure. The exception is alcohol - over a year, around 39\% of households do not buy spirits, $32 \%$ do not buy beer and $16 \%$ do not buy wine. However, over just two weeks the proportions not observed to buy are $89 \%, 84 \%$ and $71 \%$ respectively. For researchers interested in estimating price responsiveness or demand models, the ability to observe spending over an extended period is a key advantage of scanner data, since it drastically reduces the problem of how to deal with zero expenditure values.

Aside from the impact on the likelihood of observing zero expenditure, increasing the duration over which spending is recorded substantially reduces the variance in the distribution of household-level budget shares of each commodity. Figure 4.7 illustrates this for four different commodities (clockwise from top left, for bread, meat, vegetables and fish; figures for other goods available on request). This is crucial for some applications. For example, past research in the UK has used data from the two-week LCF to estimate household-specific expenditure patterns from which household-level inflation rates have been estimated (Leicester et al, 2008; Levell and Oldfield, 2011). If at least some of the variation in household budget shares is driven by the short period of observation, then these studies would overstate the variation in household-specific inflation rates across different types of household groups. 


\section{Figure 4.8. Distribution of budget shares for particular commodity groups based on period of observation, 2009}
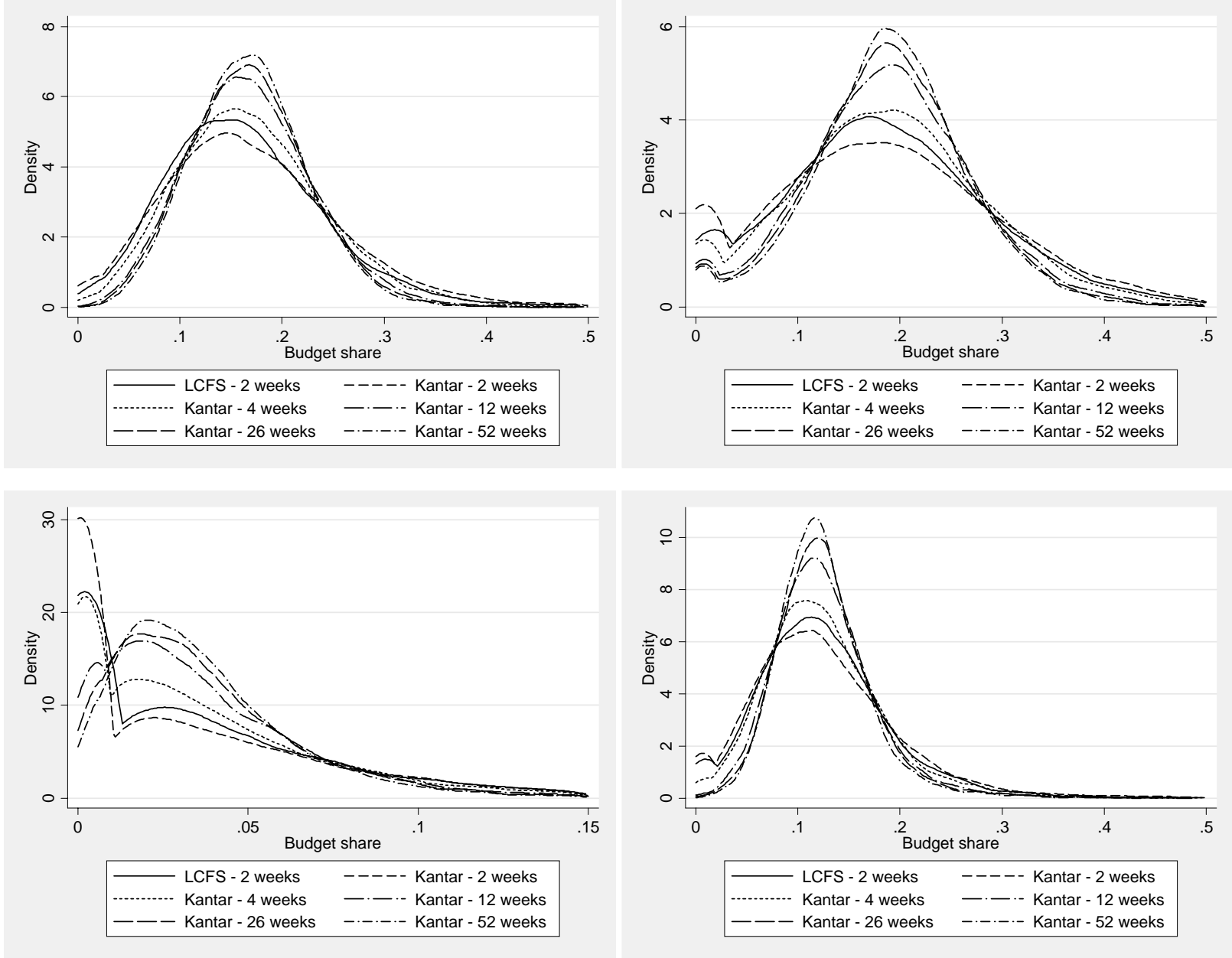

Source: Author's calculations based on 2009 LCF and Kantar Worldpanel data. Notes: Commodities shown, clockwise from top left, are bread and cereals, meat, vegetables and fish.

\section{The impact of demographics}

Are differences in expenditures across scanner and budget survey data driven by demographic effects? Recall that we select a particular non-random sample of households from the scanner data - those who do not drop out of the sample in a given year and have no long gap in their reported expenditures. If the households in this sample have characteristics which would typically make them low spenders on food at home (for example, being poorer) then this could account for the spending gap between the datasets.

Appendix A compares the observable characteristics of the LCF and Kantar ('regular reporter') samples in 2009. ${ }^{24}$ There are relatively few demographics common to both datasets. To the extent that we can strip out the effects of these common demographics, there may well be a large set of unobserved demographics, or variables observed in one dataset but not the other, which affect expenditures but on which we cannot condition. To summarise the key differences, we find that:

\footnotetext{
${ }^{24}$ In these results and for the rest of this section, we exclude a small number of households from the Kantar sample who report missing information on the number of cars they own or the employment status of the household head, and households in either survey who report equivalised average weekly spending on food and drink (over 2 weeks in the LCF sample, and over the longest uninterrupted reporting period in the Kantar sample) of less than $f 5$.
} 
- Kantar households tend to have lower income. Amongst those with non-missing incomes, only $12.5 \%(3.7 \%)$ of Kantar households have gross annual household income in excess of $£ 50,000$ $(£ 70,000)$ compared to $20.8 \%(9.9 \%)$ of LCF households.

- Kantar households are much more likely to own a home computer: $89.5 \%$ of the Kantar sample do so compared to $75.6 \%$ of the LCF sample. This probably reflects the fact that many Kantar households also participate in online surveys run by Kantar, and many use PCs to upload their expenditure records to Kantar from the scanner units.

- Only $12.9 \%$ of Kantar households do not own a car, compared to $21.6 \%$ in the LCF.

- The regional composition of the two datasets is similar. In the Kantar sample the South East and East of England are more heavily represented. Scotland appears to be slightly less represented.

- Kantar households are noticeably more middle aged: only $2.7 \%$ of the Kantar sample is headed by someone aged 80 or over compared to $7.1 \%$ of the LCF sample. Less than $1 \%$ of Kantar households are headed by someone aged 24 or under compared to $3.0 \%$ of the LCF sample.

- $56 \%$ of Kantar households are headed by a female, compared to $25 \%$ of the LCF sample.

- Kantar households are much more likely to be headed by someone who is not working $(11.3 \%$ compared to $8.6 \%$ in the LCF) or part-time employed (15.8\% working less than 30 hours, compared to just $6.1 \%$ in the LCF).

- Kantar households are much more likely to contain three or more adult members. This accords with information received from discussions with Kantar that they over-sample multiple adult households because of difficulties in obtaining purchase information from secondary shoppers.

- Kantar households have about the same number of young (pre-school aged) children as LCF households on average, but slightly more older children.

Ex ante it is not clear what these demographic differences imply for expenditures. Kantar households are poorer, on average, and less likely to be headed by a full-time employee which might mean we would expect them to spend less than LCF households. But along other dimensions they are better off: for example, being more likely to have cars and computers, and more likely to be middle aged (where lifecycle expenditures peak). Thus an empirical study is needed. We first pool observations from the LCF and Kantar samples in 2009. We take average total food and drink weekly spending figures over two weeks from the LCF and from the longest uninterrupted spending period from the Kantar sample. ${ }^{25}$ We regress the log of expenditure on a dummy variable which takes the value 1 for households from the Kantar sample, to give the raw average proportional difference between the surveys. We then add a vector of common demographic controls from the surveys to strip out observable demographic effects and see what happens to the coefficient on the Kantar dummy. Table 4.6 reports the key results, including separate results for households who do and do not report random weight items in the Kantar survey.

Table 4.6. Coefficients on Kantar dummy from regression of log average weekly food and drink expenditures, pooled Kantar and LCF sample, 2009

\begin{tabular}{|c|c|c|c|}
\hline & All households & $\begin{array}{c}\text { Records } \\
\text { random weight }\end{array}$ & $\begin{array}{c}\text { No random } \\
\text { weight }\end{array}$ \\
\hline No demographic controls & $-0.093 * * *$ & $-0.123 * * *$ & $-0.047 * * *$ \\
\hline$R^{2}$ & $\begin{array}{l}(0.011) \\
0.005\end{array}$ & $\begin{array}{c}(0.011) \\
0.010\end{array}$ & $\begin{array}{c}(0.012) \\
0.002\end{array}$ \\
\hline \multirow{2}{*}{ Controlling for common observed demographics } & $-0.182 * * *$ & $-0.179 * * *$ & $-0.179 * * *$ \\
\hline & (0.009) & $(0.010)$ & (0.013) \\
\hline $\mathrm{R}^{2}$ & 0.406 & 0.412 & 0.414 \\
\hline $\mathrm{N}$ & 20,875 & 14,643 & 11,382 \\
\hline
\end{tabular}

\footnotetext{
${ }^{25}$ As we now control for demographics, including household composition, here we use unequivalised expenditure figures.
} 
Source: Author's calculations based on 2009 LCF and Kantar Worldpanel data. Notes: Expenditure figures are unequivalised. Households with missing information on number of cars or employment status are dropped, as are those spending less than $£ 5$ (equivalised) per week on average in either survey. Demographic controls are household gross annual income group, number of cars, region, age group of household head, sex of household head, employment status of household head, number of adult males, number of adult females, numbers of children in age groups 0-4, 510 and 11-17 and numbers of people aged 65 or over. ${ }^{* *}=p<0.01 ;{ }^{* *}=p<0.05 ;^{*}=p<0.1$. Standard errors are robust. Full results are available on request.

Across all households, the raw gap between the LCF and Kantar surveys is just over 9\% - this is markedly less than the $20 \%$ seen earlier in this section, but our analysis here is based on a different (unequvalised) measure of spending and drops households with very low average food spending of less than $£ 5$ per week. Those who are asked to report random weight purchases spend $12 \%$ less than LCF households whilst those who are not asked to do so have a raw spending difference of less than $5 \%$. As above, this suggests that reducing respondent burden increases expenditures in scanner data.

Adjusting for demographic differences between the surveys, however, gives very different results. The coefficient on the Kantar dummy across all households almost doubles, suggesting a conditional expenditure gap of more than 18\%. This is consistent with Leicester and Oldfield (2009) who found the gap between Kantar and LCF spending in 2005 rose from $20 \%$ to $25 \%$ once observable demographics were taken into account. They also concluded that controlling for demographics made little difference to overall spending patterns, suggesting that the effects are similar for each commodity group. From our results, it is notable that once we adjust for demographics, there is no difference at all in the Kantar dummy amongst the groups asked or not asked to report random weight items. This suggests that much of the seeming improvement in reported spending is attributable to demographics.

To investigate the impact of demographics further, we repeat the above analysis, but now interact common observable demographics across the surveys with a Kantar dummy. The coefficients on these interactions tell us which household groups report relatively higher spending in the Kantar data than the LCF. ${ }^{26}$ Table 4.7 shows the main significant interaction terms. The base group is households in the South East of England, with incomes between $£ 10,000$ and $£ 20,000$ per year, with one car and a home computer, where the head is a male aged 45-49 and full-time employed, where there is one adult male and female but no children or anyone aged over 65 . For this group, average spending is $9 \%$ lower per week in the Kantar data than the LCF. The coefficients in Table 4.7 show the additional difference in the Kantar/LCF gap for other demographic groups; significantly positive figures suggest that households who differ from the base group only in terms of that characteristic report relatively higher expenditures in the Kantar data. Demographic variables which had no significant effects on the interaction terms are not shown. ${ }^{27}$

A striking finding is that lower income households report relatively higher spending in the Kantar data whilst higher income households report relatively lower spending. If we take LCF spending levels as 'true' (though in general we should be wary of doing so) this result is consistent with poorer households fully reporting their spending in the scanner data, and richer households being more prone to under-reporting. This might reflect the higher opportunity costs of time faced by high income participants. It could also simply reflect poorer households buying less overall and thus requiring less time and effort to scan their

\footnotetext{
${ }^{26}$ This follows the approach of Zhen et al (2009), equation 1, and Leicester and Oldfield (2009), Table 9. Zhen et al note that in their results, "[the] coefficient on the Homescan indicator variable $(\mathrm{H})$ provides a measure of the average difference in reported expenditures between Homescan and CES for the reference group. Interestingly, this coefficient is not statistically significant for any of the five [commodities]. These results suggest that much of the differences in mean expenditures [between Homescan and CES] are correlated with the observed household characteristics." (p.479). However this interpretation is not quite right - as they say, the insignificant Homescan dummy tells us that there is no difference between CES and Homescan for the reference group (in their study, households under 25 with income under \$5,000 of 'other race' living in the North East in 2002 and so on). To compare Homescan and CES for other groups requires a test of the joint significance of the Homescan coefficient and the interaction between Homescan and the other group dummy variable.

${ }^{27}$ Region is not shown. There is one significant coefficient of -0.087 in the East Midlands. Full results are available on request.
} 
purchases. Notably, there is no effect of employment status on relative Kantar expenditures, which we might also expect to be related to the opportunity costs of time..$^{28}$

Table 4.7. Interaction terms between Kantar dummy and demographic groups

\begin{tabular}{|c|c|c|c|}
\hline Variable & Coefficient & Variable & Coefficient \\
\hline Income $f 0-f 10 k$ & $+0.101^{* * *}$ & Head $<25$ & -0.019 \\
\hline Income $£ 20-£ 30 k$ & -0.032 & Head 25-29 & +0.058 \\
\hline Income $£ 30-£ 40 k$ & -0.049 & Head 30-34 & +0.003 \\
\hline Income $f 40-f 50 k$ & $-0.087 * *$ & Head 35-39 & +0.039 \\
\hline Income $£ 50-£ 60 k$ & -0.041 & Head 40-44 & -0.006 \\
\hline Income $£ 60-f 70 k$ & $-0.106 * *$ & Head 50-54 & -0.036 \\
\hline \multirow[t]{2}{*}{ Income $f 70 \mathrm{k}+$} & $-0.220 * * *$ & Head 55-59 & -0.019 \\
\hline & & Head 60-64 & $-0.087^{* *}$ \\
\hline 0 adult males & $-0.095^{*}$ & Head 65-69 & -0.093 \\
\hline 2 adult males & +0.019 & Head 70-74 & -0.070 \\
\hline \multirow[t]{2}{*}{$3+$ adult males } & $-0.205^{* * *}$ & Head 75-79 & $-0.146 *$ \\
\hline & & Head 80+ & -0.121 \\
\hline 0 adult females & $+0.100 * * *$ & & \\
\hline 2 adult females & -0.052 & Female Head & $+0.106 * *$ \\
\hline $3+$ adult females & +0.022 & & \\
\hline 1 child aged 0-4 & $-0.127 * * *$ & 1 person aged $65+$ & +0.080 \\
\hline 2 children aged 0-4 & -0.033 & 2 people aged $65+$ & $+0.137^{* *}$ \\
\hline $3+$ children aged 0-4 & $-0.330 * * *$ & $3+$ people aged $65+$ & -0.065 \\
\hline $\mathrm{N}$ & 20,875 & $R^{2}$ & 0.413 \\
\hline
\end{tabular}

Source: Author's calculations based on 2009 LCF and Kantar Worldpanel data. Notes: Left-hand side variable is the log of total weekly household average food and drink expenditure (unequivalised). Other variables controlled for are region, numbers of children aged 5-10 and 11-17, head of household employment status, numbers of cars and presence of a PC in the household. ${ }^{* * *}=p<0.01 ;^{* *}=p<0.05 ;^{*}=p<0.1$. Households with missing information on number of cars or employment status are dropped, as are those spending less than $£ 5$ (equivalised) per week on average in either survey.

Household composition also matters. Households with young children report relatively lower expenditures than those without - again, this seems plausibly related to time constraints. The coefficients on the interaction terms for older children are negative but insignificant. The number of adults also affects relative Kantar expenditures, though in different ways according to gender. For example, having three or more male adults in the household is associated with much lower relative reported spending but there is no similar effect for three or more female adults. In general, we would tend to expect that households with multiple shoppers would report relatively low spending in the scanner data compared to the LCF to the extent that spending is better reported by the main shopper than other adults; however the evidence for this based on these figures is quite weak. ${ }^{29}$

Age effects are interesting: there is some (albeit not particularly significant) evidence that relative spending is higher for households headed by younger people and lower for those headed by older people. This might be interpreted as a modal effect - for example, older households may find using the scanner

\footnotetext{
${ }^{28}$ Recall too that these estimates are based on the subset of Kantar households who report for the whole year without large spending gaps. If time costs are important then richer or full-time employed households might be less likely to be part of this sample - though as we saw earlier (and detailed in Appendix A) there is no significant effect of income or employment status on being part of this selected sample.

${ }^{29}$ Leicester and Oldfield (2009) perform a similar exercise using 2005 data from Kantar and the LCF; they find no evidence of household composition effects on relative expenditures. Unlike our estimates, they find that unemployed households report relatively more spending, but this may proxy for income which was not observed in their estimates.
} 
technology more difficult than younger households. However, it is worth noting two things that go against this conclusion. First, these results are based on the sample of Kantar households who report spending consistently - presumably households who cannot use the technology will not be included. Second, the regression also includes a variable for the number of people aged 65 or over in the household (which is the UK retirement age for males). Discussion with Kantar suggests that they believe older households to be relatively more diligent recorders of their spending, perhaps because they have more time.

A brief comparison to the results of a similar exercise in Zhen et al (2009) is worthwhile. They compare AC Nielsen and CE commodity-level expenditures, regressing spending on demographic variables interacted with a Nielsen dummy. They find a number of demographic effects on relative expenditures which are different to the findings here: for instance, they find no significant effect of the number of children, a negative impact of households with female heads, significant regional effects and generally positive effects for older ages. Other findings are more comparable: for example, lower relative spending for high income households and no clear employment status effects. What this suggests is a point raised in Section 3: findings from one particular comparison of scanner and other datasets do not necessarily translate across countries or surveys. If there were clear 'modal' effects of scanner technology we might expect the results to be quite similar across countries; instead, it seems that the particular features of each dataset might be most crucial in driving findings in different countries. Of course, the comparison we make here is not identical to that made in Zhen et al (2009) in terms of the covariates for which we can control or the selection of households, for example. One area for future work might be to explore cross country comparisons of scanner and budget survey data using, as far as possible, identical methods. Regularities which emerge from this exercise might be more credibly assigned to modal effects.

\section{The relationship between total food expenditures and expenditure patterns}

The results so far in this section have indicated that, on average, food spending levels in scanner data are lower than those in budget survey data, but that spending patterns are very similar, certainly once we strip out alcohol purchases. There may be two explanations for this. First, the Kantar and LCF surveys could be sampling similar types of households but those in the scanner data are under-recording their spending on each broad commodity group at roughly the same rate on average. Alternatively, the Kantar data could be sampling lower-spending households on average, but food spending patterns vary relatively little with total food expenditures.

To explore this latter possibility, on approach is to estimate Engel curves for each food group in the two datasets. Engel curves relate the share of total food expenditure devoted to each food commodity to the $\log$ of total food spending. For the purposes of how scanner data may be useful for statistical agencies, as discussed earlier (and detailed in Section 5), one option may be to use detailed expenditures from scanner data to impute spending patterns into budget survey data if all we knew were total spending - which is precisely this Engel relationship. Therefore a key issue is whether or not the Kantar and LCF surveys give a similar impression as to how food expenditures break down as the total food budget increases. If so, we might be more confident in make this kind of imputation. If not, it may shed more light on where particular problems in measuring expenditures arise.

This exercise is carried out in Leicester (2012) - see in particular Appendix C. He imposes no particular restriction on the shape of the Engel curves, but finds them to be approximately linear for most food groups. Most importantly, he concludes that the relationship between food expenditures and commoditylevel budget shares is very similar across datasets. The slopes of the Engel curves - where they have any slope at all - are the same. Necessities within the food budget (goods with downward sloping Engel curves) are bread and dairy products. Luxuries (with upward sloping curves) are meat, fish and fruit. For fats, vegetables, confectionery, other food and beverages, the Engel curves are broadly flat. Perhaps the biggest divergence in the Engel relationship between datasets is for other food, which shows some 
evidence of being a luxury in the LCF but where the budget share is essentially flat in total spending in the Kantar data. However there are certainly no clear cases where one dataset suggests a commodity to be a luxury and the other dataset a necessity. These findings are quite reassuring that the scanner and budget survey datasets tell similar stories about how spending patterns change with total food outlays.

\section{Using detailed scanner data to predict budget shares from aggregate spending}

Our analysis so far has focused on how scanner data compare to spending information from aggregate data and other expenditure surveys. These sorts of comparisons are useful as a source of validation for budget survey data and to inform statistical agencies of possible issues in using scanner methods as part of the data collection process.

We now assess the potential for using scanner data to impute detailed expenditures given only knowledge of total spending. A redesigned CE could decide to reduce respondent burden by asking people only about their total expenditures (or total category-level expenditures such as food spending), and then use detailed expenditure records to estimate how this breaks down. These records could come from a subset of households who agree to provide a more detailed account of their expenditures (whether using scanners, till receipts, diaries or whatever), or from external datasets like commercial scanner data. This section aims to provide evidence on how successful such an approach might be. We use scanner data to predict household-level budget shares for each commodity as a function of total expenditure and observable demographics. How well these predictions compare to actual budget shares gives a sense of how well observable demographics predict expenditure patterns, and thus how successful such an imputation approach might be. One advantage of using scanner data for this exercise is that we have detailed information on where people shop. This is useful as spending patterns appear to vary by store, so performing this exercise separately for different store types may improve the results.

We take an agnostic view on how the information on total expenditures is obtained. One approach would be a series of questions which first ask about how much households typically spend in total over a given period and then how this breaks down into broad commodity aggregates like food, clothing, leisure and so on. Further questions could be asked about the proportion of food spending in different store types, such as supermarkets, corner shops and specialist food stores. Another approach would be to use individual bank records and credit card statements to get total store-specific expenditures. This becomes more feasible as cash spending, which cannot be attributed to a particular store, declines in importance. ${ }^{30}$

We base our analysis on the 'regular reporter' sample in the 2009 Kantar data (see Section 4.2), restricting attention to households who record random weight purchases. We exclude fourteen households from this sample who have missing demographic information on cars or employment status to give a sample size of 9,494 households. We focus attention on food and non-alcoholic beverages, and use the CPI commodity categories which have formed the basis of our analysis so far to define the patterns of expenditure we wish to impute. This gives 11 categories in total.

We look at expenditures in eight different types of store. UK food retailing is dominated by the 'big four' supermarkets - Tesco, Asda, Sainsbury and Morrisons (together accounting for almost $80 \%$ of

\footnotetext{
${ }^{30}$ Figures from the UK Payments Council $(2010,2011)$, for example, suggest that about $68 \%$ of retail purchases by value were on credit and debit cards in the second quarter of 2011, compared to about $61 \%$ in 2008 .
} 
expenditure in our data) - and we look at each of these stores separately. ${ }^{31}$ Other supermarket chains are grouped according to quality segment: discount supermarkets (Aldi, Lidl, Netto, Cash and Carry stores), quality supermarkets (Waitrose, Marks \& Spencer) and other supermarkets (Co-op, Somerfield, Iceland, other chains). Remaining stores are then grouped together into a single category for local and high street expenditures - largely shopping in specialist food retailers (butcher shops, delicatessens and so on) and corner shops. These account for a low share of spending, suggesting there is little to be gained from disaggregating them still further. Table 5.1 shows the eight store types considered and their market shares by expenditure. Figure 5.1 shows how total food and drink expenditure breaks down for each store across the 11 commodities we consider. ${ }^{32}$

Table 5.1. Store types in the analysis and market shares, 2009

\begin{tabular}{r|c}
\hline \multicolumn{1}{|c|}{ Store } & Market share $(\%$, by expenditure) \\
\hline Tesco & 31.5 \\
Asda & 18.8 \\
Sainsbury & 14.8 \\
Morrisons & 13.6 \\
Other supermarkets & 7.2 \\
Discount stores & 6.0 \\
Quality stores & 4.5 \\
Local / High Street stores & 3.7 \\
\hline
\end{tabular}

Source: Author's calculations based on 2009 Kantar Worldpanel data.

Figure 5.1. CPI commodity budget shares, by store type, 2009

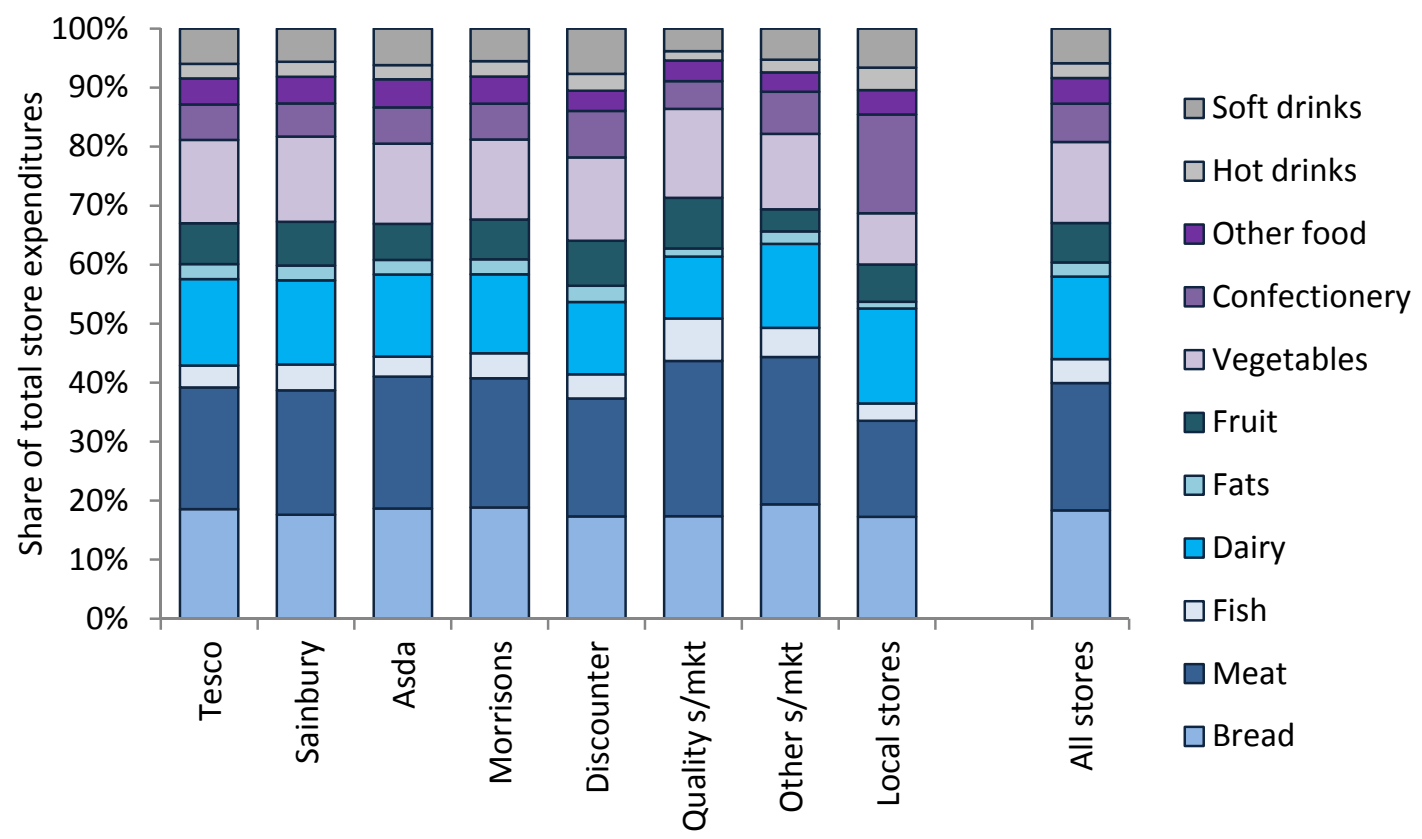

Source: Author's calculations based on 2009 Kantar Worldpanel data.

There are some differences in expenditure patterns across stores. Notably, in discount supermarkets, soft drinks and confectionery account for a larger share of spending than across all stores, whilst dairy and meat products account for smaller shares. In quality supermarkets, fruit, vegetables, meat and fish account for a larger share and dairy, confectionery and soft drinks account for lower shares. The most

\footnotetext{
${ }^{31}$ Spending in the big four supermarkets includes spending in all formats of stores (e.g. Tesco Extra, Tesco Express). Online expenditures are allocated to the appropriate store.

${ }^{32}$ These estimates are based on the full 2009 Kantar sample, rather than the selected 'good reporter' sample.
} 
striking differences are in local stores - for example, across all stores confectionery accounts for about $6.5 \%$ of expenditure but in local stores the share is $16.7 \%$. This probably reflects the different sorts of shopping done in local stores which are more associated with top-up and impulse purchases.

If households systematically under-report different types of expenditure in scanner data, imputed budget shares would be biased. A useful check would be to compare expenditure patterns at the store level obtained from store data to those seen in the in-home scanner data. The former would presumably be complete, accurate records of store-specific sales patterns. We do not have access to such data and are not aware of any comparisons having been made of this nature. It would, though, be a useful line of inquiry for statistical agencies thinking of using in-home scanner data.

Using the Kantar sample, we calculate total annual household-level spending during 2009 across each of the store types defined above, broken down by the $11 \mathrm{CPI}$ food and drink commodities. This gives us household-store specific budget shares. Weighting these by the share of each household's spending in each store type gives the household's overall observed budget share for each commodity. We then use seemingly-unrelated OLS regression methods to estimate a system of equations for store-specific budget shares for each commodity:

$$
w_{i j}^{k}=\alpha+\beta \ln \left(X_{i j}\right)+Z_{i}^{\prime} \gamma+\varepsilon_{i j}^{k}
$$

where $w_{i j}^{k}$ is the budget share of household $i$ in store $j$ for commodity $k, X_{i j}$ is the total spend of household $i$ in store $j$, and $\boldsymbol{Z}_{i}$ is a vector of observable demographic household characteristics. ${ }^{33}$ The system is run separately for each store type, allowing for store-specific Engel curves and for demographic effects to vary across store types. From the equation we predict the expected budget share $\widehat{w}_{i j}^{k}$. To ensure the predicted budget shares add up to 1 , we estimate the results for 10 of the 11 commodities, excluding 'other food', for which the predicted budget share is estimated as a residual. These predicted shares are then weighted into an overall predicted household-specific budget share for each commodity using the household-store specific expenditure weights.

Detailed regression results for each store type are available on request. As a summary of the predictive power of these regressions, Table 5.2 reports the $\mathrm{R}^{2}$ estimates by store and commodity (the number of observations varies because the equations are estimated only for households with positive expenditures in each store during the year). The key conclusion is that observable characteristics, including total store expenditures, have little predictive power for store-specific commodity budget shares. This implies that there is a large amount of unobserved heterogeneity in within-store spending patterns. Of course, our estimates here are somewhat constrained by the limited set of demographic variables available in the Kantar data, though our covariates include most of the usual explanatory variables such as age, household composition and income that would feature in demand models.

\footnotetext{
${ }^{33}$ The model includes gross household income, region, household composition (numbers of adult males, females, children in different age groups and people aged 65+), the age band and sex of the household head, the employment status of the household head, the number of cars and whether or not there is a home computer. Because we use annual expenditures we do not include any seasonal controls. We experimented with various specifications, including adding a squared term on total expenditure to allow store-specific Engel curves to be non-linear, but found this not to be important. We also experimented with including the share of total food spending by household $i$ in store $j$ as a right-hand side covariate, the idea being to capture variations in budget shares amongst households who rely on a particular store type for most of their shopping against those who use the store more as a top up or secondary store. We found this had little additional explanatory power for the model but led to a substantial rise in the number of predicted budget shares which were negative. Similarly, conditioning the regression estimates on households who spent more than some minimum amount in each store type made the predicted number of negative budget shares much larger, presumably because the model did not perform well out of sample for those with low total store expenditures.
} 
Table 5.2. Explanatory power $\left(R^{2}\right)$ of store-specific commodity budget share model

\begin{tabular}{r|cccccccc}
\hline & Tesco & Sains & Asda & Morris & Discount & Quality & Other & Local \\
\hline $\mathrm{N}$ & 7,988 & 6,026 & 6,558 & 5,970 & 6,054 & 4,736 & 7,109 & 7,512 \\
\hline Bread & 0.055 & 0.055 & 0.039 & 0.045 & 0.021 & 0.078 & 0.029 & 0.028 \\
Meat & 0.038 & 0.044 & 0.038 & 0.050 & 0.046 & 0.064 & 0.050 & 0.085 \\
Fish & 0.034 & 0.032 & 0.025 & 0.036 & 0.028 & 0.047 & 0.018 & 0.025 \\
Dairy & 0.013 & 0.017 & 0.019 & 0.023 & 0.023 & 0.032 & 0.019 & 0.090 \\
Fats & 0.037 & 0.021 & 0.021 & 0.026 & 0.018 & 0.018 & 0.020 & 0.012 \\
Fruit & 0.045 & 0.029 & 0.026 & 0.041 & 0.028 & 0.023 & 0.030 & 0.063 \\
Vegetables & 0.028 & 0.028 & 0.021 & 0.025 & 0.017 & 0.036 & 0.012 & 0.015 \\
Sugars & 0.029 & 0.034 & 0.024 & 0.020 & 0.030 & 0.036 & 0.017 & 0.109 \\
Hot beverages & 0.026 & 0.019 & 0.018 & 0.019 & 0.019 & 0.016 & 0.014 & 0.020 \\
Soft drinks & 0.037 & 0.035 & 0.033 & 0.045 & 0.038 & 0.024 & 0.08 & 0.070 \\
\hline
\end{tabular}

Source: Author's calculations based on 2009 Kantar Worldpanel data.

Appendix B shows the distribution of actual and predicted household-level budget shares resulting from this modelling exercise. Broadly, this approach captures the average shares quite well but not the distribution: the modelled shares lie over a much narrower range than is observed in the data.

One way in which we might be able to capture some of this unobserved heterogeneity is to use the variance of the error terms from the model to predict a (mean-zero) vector of random 'noise' for each store-specific budget share which is then added to the predicted share. We could also use more sophisticated imputation and econometric methods to predict the budget shares. For example, a particular problem with the OLS approach is that households do not buy from each commodity group at each store type they visit. This is particularly problematic once we condition on store type: for example, more than half of households who ever use local stores buy no meat, fish, fats or hot beverages at all, even over a year. Even within the big four supermarkets, more than $30 \%$ of shoppers never buy from the hot beverage category, more than $25 \%$ buy no fish and more than $20 \%$ no fats. This problem might suggest running a system of Tobit equations for each store to help better model the zero shares. This would also mean predicted shares could not be negative: in our estimates, around $16 \%$ of households are predicted to have at least one negative budget share (these households are dropped from the results in Appendix B). However, the main intention of this exercise is to assess the extent to which observable covariates are able to explain variation in within-store spending patterns, for which these simple OLS estimates provide initial evidence. If this approach were taken further by statistical agencies then more attention should be paid to the precise econometric methods used.

The findings in this section suggest that attempts to use detailed store-level expenditure patterns to impute household-specific budget shares if we observe only total spending may not be particularly successful. There is a large amount of unobserved heterogeneity in store-specific expenditure patterns not captured by the usual demographic covariates commonly featured in models of household spending. We may be able to do a reasonable job of predicting average budget shares but would be unlikely to replicate the distribution of actual budget shares, though of course more sophisticated econometrics may get us further towards that goal. Whilst from the perspective of estimating CPI budget shares getting the average right is the key objective, from a research perspective having accurate household-specific budget shares is vital (for example, in demand modelling and accurately estimating household responsiveness to price shocks, or in estimating the distributional consequences of policies, or how inflation rates vary across households). A consumer budget survey that relied heavily on imputed expenditure patterns might therefore be very undesirable. At the very least it would seem important to have a large enough subset of respondents provide detailed expenditure data without imputation, even if imputation were used to 'fill in' the spending patterns for households unable or unwilling to provide more than broad aggregates. 


\section{Summary and conclusions}

In-home scanner data offer a hugely exciting opportunity for researchers to explore detailed questions about household expenditure behaviour and firm pricing decisions. Scanner datasets and scanners as a method of data collection are also potentially of interest for statistical agencies in terms of how they might inform, or be integrated into, budget survey data. Existing scanner data typically only cover a relatively narrow subset of total expenditures. Nevertheless, in terms of the potential for using existing commercial scanner datasets, organisations like the ONS or BLS may see three key opportunities:

1. Comparison and validation - do expenditures reported in scanner data tell a different story to those reported in budget survey data, and what can we learn from a more micro analysis of differences in spending across households?

2. Detail - having full knowledge of precisely what is bought helps inform the choice of representative items for inflation measurement, the weights that should be given to these items at the lowest level of disaggregation in inflation calculations, the importance of product turnover (particularly in dynamic sectors like grocery retail) and so on.

3. Duration - scanner data report spending over a long time period whereas budget surveys collect detailed spending only for a short duration. The scanner data can therefore give insight into whether short observation periods are appropriate even for non-durable commodities like food and whether the distribution of spending patterns across households is well measured.

However, crucial for any use of scanner data is an understanding of data quality. Researchers and data collectors have, over a long period, developed a good knowledge of the strengths and weaknesses of budget survey data. Scanner data are more novel. The evidence in this paper and the previous literature point to some consistent differences between scanner data and budget survey data collected via diaries in particular, that expenditures are lower in scanner data, that expenditures appear to be particularly low for certain commodity groups like alcohol and soft drinks, that it matters whether or not participants have to record non-barcoded products, and that there are differences in the relative under-reporting across household groups (in particular relating to income and numbers of children, which plausibly reflect time constraints). These differences point to modal effects. However, in some cases, differences between scanner and budget survey expenditures which might in isolation be attributed to survey mode may, in fact, be specific to the particular datasets studied. This implies that researchers and data collectors would need to be aware of the features and methods of the particular scanner data they are using in order to assess its likely benefits. Detailed cross-country comparisons of scanner and budget survey data which, as far as possible, apply common methods would be a useful way to tease out modal effects. Collaboration between national statistical agencies and researchers in different countries to share knowledge and carry out such research would be desirable. For example, statistical agencies have access to much more disaggregate information about households and shopping trips from the budget survey than are made available to external researchers. This information could give more detailed insight into the differences between diary-based and scanner expenditures, and so should be made available for this kind of analysis. Another possibility would be for statistical agencies and commercial data collectors to collaborate directly. For example, to address issues around sample representativeness in scanner surveys, agencies could supply a household sample drawn at random from the population and ask the data collectors to try and incorporate them into the sample, seeing who refuses, who drops out quickly, who appears to cooperate effectively and so on. In some countries, notably Nordic ones, detailed population-level data linked to identification records is maintained which would allow for detailed analysis of these sorts of issues to be carried out.

Our comparisons between scanner data and budget survey data point to a number of key conclusions. Most notably, scanner data are prone to large numbers of weeks in which no purchases at all are recorded, 
even by ostensibly active households. We do not have a clear understanding of what drives this, but these zeroes explain a large part of the raw gap between scanner and budget survey expenditures. However, even when we restrict ourselves to a sample of households who are faithful reporters, and eliminate zero spending weeks altogether, a large expenditure gap remains. Evidence from British data suggests that this gap is not accounted for by observable demographic differences between samples. More reassuringly, patterns of spending across surveys are similar even though the levels are different, and re-weighting the food CPI using survey-specific budget shares has very little impact on inflation rates. The relationship between total expenditures and commodity-level budget shares is also very similar across surveys.

We find compelling evidence that asking households to record detailed expenditures over a short horizon leads to an inaccurate picture of the distribution of commodity-level budget shares, but not average spending patterns. The two week duration of budget diaries both in the LCF and the CE is probably not long enough to get a good measure of true food consumption patterns, generating too much variability in the distribution of budget shares and too many zero expenditures for particular commodities.

We also consider the possibility that scanner data may be useful to 'drill down' into aggregate store-level expenditures and impute commodity-specific expenditures. We find substantial differences in expenditure patterns across store types which supports breaking down spending by store rather than imputing based on total spending in all stores. However, we find very little relationship between expenditure patterns and observable covariates. Thus whilst an imputation approach might get the averages broadly right, the distribution of imputed budget shares is much less dispersed than the distribution of observed budget shares. More sophisticated imputation or econometric methods may help, and we could also be hamstrung in this analysis by the relatively limited set of demographic information in the scanner data. In general, though, it would not appear to be sensible to rely too heavily on imputation methods to obtain detailed measures of spending.

As mentioned in the introduction, rather than relying on existing commercial scanner data, agencies like the BLS or ONS might be interested in the idea of establishing their own panel of households using scanner methods to record their spending on an ongoing basis. If this were integrated with the budget survey, there would be clear benefits in terms of immediately stripping out demographic differences as a source of variation between scanner and other expenditure data, and in ensuring that the scanner sample were collected using proper random sampling methods. It would also allow, for the first time, detailed scanner data for particular commodities to be linked to more general expenditure patterns. Existing scanner datasets are limited in coverage to food at home and a small number of non-food purchases. Knowing how much households spent on food out as well as other expenditure categories would be extremely beneficial, as would any other links that could be made between the detailed information in scanner data and wider household characteristics relating to health, dwelling characteristics, durable ownership and so on. A new dataset collected by a statistical agency would also enable experimental analysis of the impact of survey mode, different scanner devices, different reporting requirements (e.g. non-barcoded items), different incentives for participation, and so on. By providing 'gold standard' evidence of these issues using randomised trials, this would be extremely valuable not just for the agencies themselves but also for researchers into survey design and data users.

We end by offering some thoughts, based on this paper and previous studies, on other ways in which new scanner data could improve on existing commercial datasets. Firstly, one of the major limitations of the Kantar Worldpanel relative to the LCF (and other datasets collected by statistical agencies and used frequently by researchers) is the relatively poor demographic information. Scanner data are collected for commercial marketing and market research purposes. The main clients are retailers and grocery manufacturers who may need only relatively basic demographic profiles of the households in the sample. 
Whilst the data follow the same households over time, one of the key findings from previous analysis of the Kantar data is that important demographic transitions such as changes in employment status are not well recorded. This may not be true of scanner datasets in general, but we are not aware of research which has looked at this question for other data. Improperly recorded transitions hugely restrict the usefulness of the panel nature of the data (for example, in analysing how detailed food spending behaviour changes around retirement or in response to unexpected income shocks). New scanner data collected by statistical agencies could presumably obtain much more detailed demographic information about household members to match the kinds of data familiar in budget surveys, and ideally would also take more care to ensure changes in demographics were captured if the same households were followed for an extended period. This should extend not only to knowing whether a transition occurred but also when.

Secondly, a key unresolved problem with scanner data is to be the high prevalence of weeks in which no expenditures are reported. This does not match up to budget survey data. Understanding this better would be a key contribution of a new scanner dataset. For example, if no expenditures are recorded over a week or a fortnight, households could be prompted with some form of contact from the statistical agency to see what has driven this and then code this into the data. This would allow the agency and researchers to distinguish genuine zeroes - holidays, weeks in which households simply used stocks of food or ate out and so on - from non-genuine ones where trips were made but not reported for whatever reason. Indeed it might be possible in this latter case to get retrospective information (from till receipts or recall questions) or to impute missing trips altogether.

Thirdly, it seems important that any scanner data aims to be, as far as possible, a complete record of the shopping trip. Most existing panels now require only a subset of respondents to report non-barcoded purchases. In the Kantar data, this was justified by better reporting compliance for non-barcoded items. However, our analysis suggests that this result is at least partly driven by demographic differences between those who do and do not report non-barcoded purchases. It may also be differences in the type of scanner device, rather than the lack of random weight reporting which gives this result. Our preference would be that households were asked to record random weight purchases as well since not doing so risks substantial bias in estimating consumption of certain commodities, particularly fruit and vegetables. The aim should be to minimise the additional burden imposed by this requirement. One problem for commercial scanner data is the need to include very detailed product characteristics which needed to be manually input by respondents for random weight items (e.g. the country of origin of different fruits, whether organic, the weight purchased). To the extent that such details are not needed by statistical agencies they could be dispensed with altogether, or taken where available from till receipts, or imputed. If recording random weight items simply required scanning a barcode from a generic booklet or tapping an icon on the barcode reader itself then it may be little more onerous than recording barcoded products.

Finally, we would certainly advocate that any new scanner data made use of till receipts as well as the inhome scanner. Studies of Nielsen data highlighted the problems of relying on imputed prices obtained from centralised store-level databases given the growth of personalised pricing through vouchers and loyalty cards, as well as store-specific special offers. Participants should be encouraged to send in receipts, and it may be that technology could enable this to be done digitally (scanned receipts or optical character recognition devices attached to computers) to integrate it with the data collection process more closely. 


\section{References}

Ahmed, N., M. Brzozowski and T. Crossley (2006), Measurement Errors in Recall Food Consumption Data, IFS Working Paper 06/21 (http://www.ifs.org.uk/publications/3752)

Aguiar, M. and E. Hurst (2007), 'Life-cycle prices and production', American Economic Review, 97, 15331559

Attanasio, O., E. Battistin and A. Leicester (2006), From Micro to Macro, from Poor to Rich: Consumption and Income in the UK and the US, National Poverty Center conference paper

(http://www.npc.umich.edu/news/events/consumption06 agenda/Attanasio-Battistin-Leicester.pdf)

Ayers, R., P. Hossack and C. Payne (2010), Living Costs and Food Survey Technical Report for the Survey Year January - December 2009, Office for National Statistics

Blow, L., A. Leicester and Z. Smith (2004), Consumption Trends in the UK, 1975 - 99, IFS Report 65, London: IFS (http://www.ifs.org.uk/comms/r65.pdf)

Brewer, M., A. Goodman and A. Leicester (2006), Household Spending in Britain: What Can it Teach Us About Poverty?, Bristol: The Policy Press (http://www.jrf.org.uk/sites/files/irf/9781861348555.pdf)

Broda, C., E. Leibtag and D. E. Weinstein (2009), 'The role of prices in measuring the poor's living standards', Journal of Economic Perspectives, 23(2), 77-97

Cole, N. (2011), Design of the National Household Food Acquisition and Purchase Survey (FoodAPS), Presentation to Committee on National Statistics Household Survey Producers Workshop (http://www.bls.gov/cex/hhsrvywrkshp cole.pdf)

DEFRA (2011), Attitudes and Behaviours Around Sustainable Food Purchasing, London: DEFRA (http://www.defra.gov.uk/statistics/files/defra-stats-foodfarm-food-attitudes-report-110406mainreport.pdf)

Duly, A., T. Garner, E. Keil, S. Reyes-Morales and C. Wirth (2003), The Consumer Expenditure Survey and AC Nielsen Survey: a Data Comparison Study, unpublished internal BLS document.

Einav, L., E. Leibtag and A. Nevo (2008), Not-so-classical measurement errors: a validation study of Homescan, Stanford Institute for Economic Policy Research Discussion Paper 08-07 (http://wwwsiepr.stanford.edu/repec/sip/08-007.pdf)

Feenstra, R. C. and M. D. Shapiro (2003), Scanner Data and Price Indexes, Chicago: University of Chicago Press (http://www.nber.org/books/feen03-1/)

Garner, T., R. McClelland and W. Passero (2009), Strengths and Weaknesses of the Consumer Expenditure Survey from a BLS Perspective (http://www.bls.gov/cex/pce compare 199207.pdf)

Griffith, R., E. Leibtag, A. Leicester and A. Nevo (2009), 'Consumer shopping behavior: how much do consumers save?', Journal of Economic Perspectives, 23(2), 99-120 
Griffith, R. and M. O'Connell (2009), 'The use of scanner data for research into nutrition', Fiscal Studies, 30 (3-4), 339-365

Harding, M., E. Leibtag and M. Lovenheim (2012, forthcoming), 'The heterogeneous geographic and socioeconomic incidence of cigarette taxes: evidence from Nielsen Homescan data', American Economic Journal: Economic Policy

Harris, J. M. (2005), 'Using Homescan data and complex survey design techniques to estimate convenience food expenditures', American Agricultural Economics Association Conference Paper (http://ageconsearch.umn.edu/bitstream/19344/1/sp05ha07.pdf)

Huffman, S. and H. Jensen (2004), Demand for Enhanced Foods and the Value of Nutritional Enhancements of Food: the Case of Margarines, American Agricultural Economics Association Conference Paper (http://ageconsearch.umn.edu/bitstream/20205/1/sp04hu05.pdf)

Jin, W., R. Joyce, D. Philips and L. Sibieta (2011), Poverty and Inequality in the UK: 2011, IFS Commentary 118, London: IFS (http://www.ifs.org.uk/comms/comm118.pdf)

Leicester, A. (2012), How Might In-Home Scanner Technology be Used in Budget Surveys?, IFS Working Paper 12/01, London: IFS (http://www.ifs.org.uk/wps/wp1201.pdf)

Leicester, A., C. O'Dea and Z. Oldfield (2008), The Inflation Experience of Older Households, IFS Commentary 106, London: IFS (http://www.ifs.org.uk/comms/comm106.pdf)

Leicester, A. and Z. Oldfield (2009), An analysis of consumer panel data, IFS Working Paper W09/09 (http://www.ifs.org.uk/publications/4468); see also Leicester, A. and Z. Oldfield (2009), 'Using scanner technology to collect expenditure data', Fiscal Studies, 30 (3-4), 309-337

Levell, P. and Z. Oldfield (2011), The Spending Patterns and Inflation Experience of Low-Income Households Over the Past Decade, IFS Commentary119, London: IFS (http://www.ifs.org.uk/comms/comm119.pdf)

Lusk, J. L. and K. Brooks (2011), 'Who participates in household scanning panels?', American Journal of Agricultural Economics, 93(1), 226-240

Mathiowetz, N., K. Olson and C. Kennedy (2011), Redesign Options for the Consumer Expenditure Survey (http://www.bls.gov/cex/redwrkshp_pap abtsrbirecommend.pdf)

O'Dea, C. and T. Crossley (2010), The Wealth and Saving of UK Families on the Eve of the Crisis, IFS Report 71, London: IFS (http://www.ifs.org.uk/comms/r71.pdf)

Office for National Statistics (2010a), Consumer Trends, Q2 2010, Newport: ONS

(http://www.ons.gov.uk/ons/rel/consumer-trends/consumer-trends/q2-2010/consumer-trends-no-57.pdf)

Office for National Statistics (2010b), Consumer Price Indices Technical Manual: 2010 Edition, Newport: ONS (http://www.ons.gov.uk/ons/guide-method/user-guidance/prices/cpi-and-rpi/consumer-priceindices-technical-manual---2010.pdf) 
Parker, J., N. Souleles and C. Carroll (2013), "The benefits of panel data on expenditures in the Consumer Expenditure Survey' in Improving the Measurement of Consumption Expenditure, Chicago, IL: University of Chicago Press (http://www.econ2.jhu.edu/people/ccarroll/papers/ParkerSoulelesCarroll/)

Perloff, J. M. and M. Denbaly (2007), 'Data needs for consumer and retail firm studies', American Journal of Agricultural Economics, 89 (5), 1282-1287

Slesnick, D. (2001), Consumption and Social Welfare, New York: Cambridge University Press

Tanner, S. (1998), 'How much do consumers spend? Comparing the FES and National Accounts', in Banks, J. and P. Johnson (eds.), How Reliable is the Family Expenditure Survey? Trends in Incomes and Expenditures Over Time, IFS Report 57, London: IFS (http://www.ifs.org.uk/comms/r57.pdf)

Triplett, J. (1997), Measuring Consumption: the Post-1973 Slowdown and the Research Issues (http://www.brookings.edu/ /media/Files/rc/articles/1997/0702useconomics triplett/19970702.pdf)

Tucker, C. (2011), Using Multiple Data Sources and Methods to Improve Estimates in Surveys, presented at BLS Household Survey Producers Workshop, June 2011

(http://www.bls.gov/cex/hhsrvywrkshp tucker.pdf)

UK Payments Council (2010), The Way We Pay 2010: The UK's Payment Revolution (http://www.paymentscouncil.org.uk/files/payments council/the way we pay 2010 final.pdf)

UK Payments Council (2011), Quarterly Statistical Report Q2 2011

(http://www.paymentscouncil.org.uk/files/payments_council/minutes_of_payments_council_board/stati stical release 2011 q2.pdf)

USDA (2009), The Consumer Data and Information Program: Sowing the Seeds of Research (http://www.ers.usda.gov/publications/ap/ap041/ap041.pdf)

Westat (2011a), Data Capture Technologies and Financial Software for Collecting Consumer Expenditure Data (http://www.bls.gov/cex/ceother2011westat.pdf)

Westat (2011b), Redesign Options for the Consumer Expenditure Survey (http://www.bls.gov/cex/redwrkshp pap westatrecommend.pdf)

Zhen, C., J. L. Taylor, M. K. Muth and E. Leibtag (2009), 'Understanding differences in self-reported expenditures between household scanner data and diary survey data: a comparison of Homescan and Consumer Expenditure Survey', Review of Agricultural Economics, 31(3), 470-492 


\section{Appendix A: Observable demographic comparisons}

The tables below compare observable demographic characteristics of the LCF 2009 sample (excluding Northern Ireland) and the Kantar 2009 'regular reporter' sample (see Section 4.2). Respective sample sizes are 5,150 and 15,752 households.

\section{Gross annual household income}

\begin{tabular}{r|cc|ccc}
\hline & \multicolumn{3}{|c|}{ All } & \multicolumn{3}{c}{ Excluding unknown } \\
\cline { 2 - 6 } & Kantar \% & LCF $\%$ & Kantar \% & LCF \% & $\mathrm{K} \div \mathrm{LCF}$ \\
\hline Unknown & 18.1 & 0.0 & & & \\
$<£ 10,000$ & 9.9 & 13.4 & 12.1 & 13.4 & 0.90 \\
$£ 10,000-£ 19,999$ & 22.4 & 23.9 & 27.3 & 23.9 & 1.15 \\
$£ 20,000-£ 29,999$ & 17.7 & 17.9 & 21.6 & 17.9 & 1.20 \\
$£ 30,000-£ 39,999$ & 13.1 & 13.6 & 15.9 & 13.6 & 1.17 \\
$£ 40,000-£ 49,999$ & 8.6 & 10.4 & 10.5 & 10.4 & 1.01 \\
$£ 50,000-£ 59,999$ & 4.9 & 6.6 & 5.9 & 6.6 & 0.90 \\
$£ 60,000-£ 69,999$ & 2.3 & 4.3 & 2.9 & 4.3 & 0.67 \\
$\geq £ 70,000$ & 3.1 & 9.9 & 3.7 & 9.9 & 0.38 \\
\hline
\end{tabular}

Computer in the household?

\begin{tabular}{r|ccc}
\hline & Kantar \% & LCF $\%$ & K $\div$ LCF \\
\hline No & 10.5 & 24.2 & 0.43 \\
Yes & 89.5 & 75.8 & 1.18 \\
\hline
\end{tabular}

Number of cars

\begin{tabular}{r|ccc}
\hline & Kantar \% & LCF $\%$ & K $\div$ LCF \\
\hline Zero & 12.9 & 21.6 & 0.59 \\
One & 50.7 & 45.0 & 1.13 \\
Two or more & 36.5 & 33.4 & 1.09 \\
\hline
\end{tabular}

\section{Region}

\begin{tabular}{r|ccc}
\hline & Kantar \% & LCF $\%$ & $\mathrm{~K} \div \mathrm{LCF}$ \\
\hline North East & 4.8 & 4.5 & 1.07 \\
North West & 11.6 & 11.2 & 1.04 \\
Yorks \& Humber & 8.8 & 9.2 & 0.95 \\
East Midlands & 8.5 & 7.5 & 1.13 \\
West Midlands & 9.2 & 10.1 & 0.91 \\
East of England & 10.8 & 9.6 & 1.13 \\
London & 8.5 & 8.8 & 0.96 \\
South East & 15.1 & 13.4 & 1.12 \\
South West & 9.5 & 10.0 & 0.95 \\
Wales & 5.1 & 5.2 & 0.97 \\
Scotland & 8.2 & 10.4 & 0.79 \\
North East & 4.8 & 4.5 & 1.07 \\
\hline
\end{tabular}

Gender of household head

\begin{tabular}{r|ccc}
\hline & Kantar \% & LCF \% & K $\div$ LCF \\
\hline Male & 44.0 & 74.7 & 0.59 \\
Female & 56.0 & 25.3 & 2.21 \\
\hline
\end{tabular}




\begin{tabular}{r|ccc}
\hline & Kantar \% & LCF $\%$ & K $\div$ LCF \\
\hline$<25$ & 0.6 & 3.0 & 0.20 \\
$25-29$ & 4.0 & 5.3 & 0.75 \\
$30-34$ & 7.5 & 7.1 & 1.06 \\
$35-39$ & 10.1 & 8.7 & 1.15 \\
$40-44$ & 11.6 & 9.9 & 1.16 \\
$45-49$ & 10.6 & 10.1 & 1.05 \\
$50-54$ & 10.3 & 9.0 & 1.14 \\
$55-59$ & 10.6 & 9.7 & 1.09 \\
$60-64$ & 9.9 & 9.6 & 1.03 \\
$65-69$ & 8.3 & 7.7 & 1.08 \\
$70-74$ & 8.6 & 6.8 & 1.26 \\
$75-79$ & 5.4 & 6.0 & 0.90 \\
$\geq 80$ & 2.7 & 7.1 & 0.38 \\
\hline
\end{tabular}

\section{Employment status of household head}

\begin{tabular}{r|ccc}
\hline & Kantar \% & LCF $\%$ & $\mathrm{~K} \div \mathrm{LCF}$ \\
\hline Works 30+ hours & 41.8 & 51.5 & 0.81 \\
Works 8-29 hours & 13.7 & 5.7 & 2.42 \\
Works <8 hours & 2.1 & 0.4 & 5.68 \\
Unemployed & 1.9 & 3.9 & 0.50 \\
Retired & 28.6 & 29.1 & 0.98 \\
Full-time education & 0.5 & 0.9 & 0.60 \\
Not working & 11.3 & 8.6 & 1.32 \\
\hline
\end{tabular}

Number of adults (aged 18+)

\begin{tabular}{r|ccc|ccc}
\hline & \multicolumn{3}{|c|}{ Males } & \multicolumn{3}{c}{ Females } \\
\cline { 2 - 7 } & Kantar \% & LCF $\%$ & $\mathrm{~K} \div$ LCF & Kantar \% & LCF \% & $\mathrm{K} \div$ LCF \\
\hline Zero & 16.5 & 22.7 & 0.72 & 9.4 & 13.5 & 0.69 \\
One & 71.6 & 69.2 & 1.03 & 79.7 & 78.7 & 1.01 \\
Two & 10.1 & 7.1 & 1.43 & 9.6 & 6.8 & 1.40 \\
Three+ & 1.8 & 1.0 & 1.89 & 1.4 & 1.0 & 1.45 \\
\hline
\end{tabular}

Number of children

\begin{tabular}{r|ccc|ccc|ccc}
\hline & \multicolumn{3}{|c|}{ Ages 0-4 } & \multicolumn{3}{c|}{ Ages 5-10 } & \multicolumn{3}{c}{ Ages 11-17 } \\
\cline { 2 - 10 } & Kant \% & LCF \% & $\mathrm{K} \div \mathrm{L}$ & Kant \% & LCF \% & $\mathrm{K} \div \mathrm{L}$ & Kant \% & LCF \% & $\mathrm{K} \div \mathrm{L}$ \\
\hline Zero & 87.9 & 87.7 & 1.00 & 84.4 & 87.5 & 0.96 & 82.9 & 85.5 & 0.97 \\
One & 9.4 & 9.6 & 0.97 & 11.4 & 9.0 & 1.27 & 11.7 & 9.6 & 1.22 \\
Two & 2.6 & 2.4 & 1.10 & 3.8 & 3.3 & 1.16 & 4.7 & 4.3 & 1.10 \\
Three+ & 0.1 & 0.3 & 0.52 & 0.4 & 0.3 & 1.59 & 0.7 & 0.6 & 1.13 \\
\hline
\end{tabular}

Number of people age 65+

\begin{tabular}{r|ccc}
\hline & Kantar \% & LCF $\%$ & $\mathrm{~K} \div$ LCF \\
\hline Zero & 71.0 & 70.9 & 1.00 \\
One & 16.5 & 18.6 & 0.89 \\
Two & 12.5 & 10.5 & 1.19 \\
Three+ & 0.0 & 0.1 & 0.33 \\
\hline
\end{tabular}




\section{Appendix B: Actual and predicted household-level budget shares, by commodity, 2009}
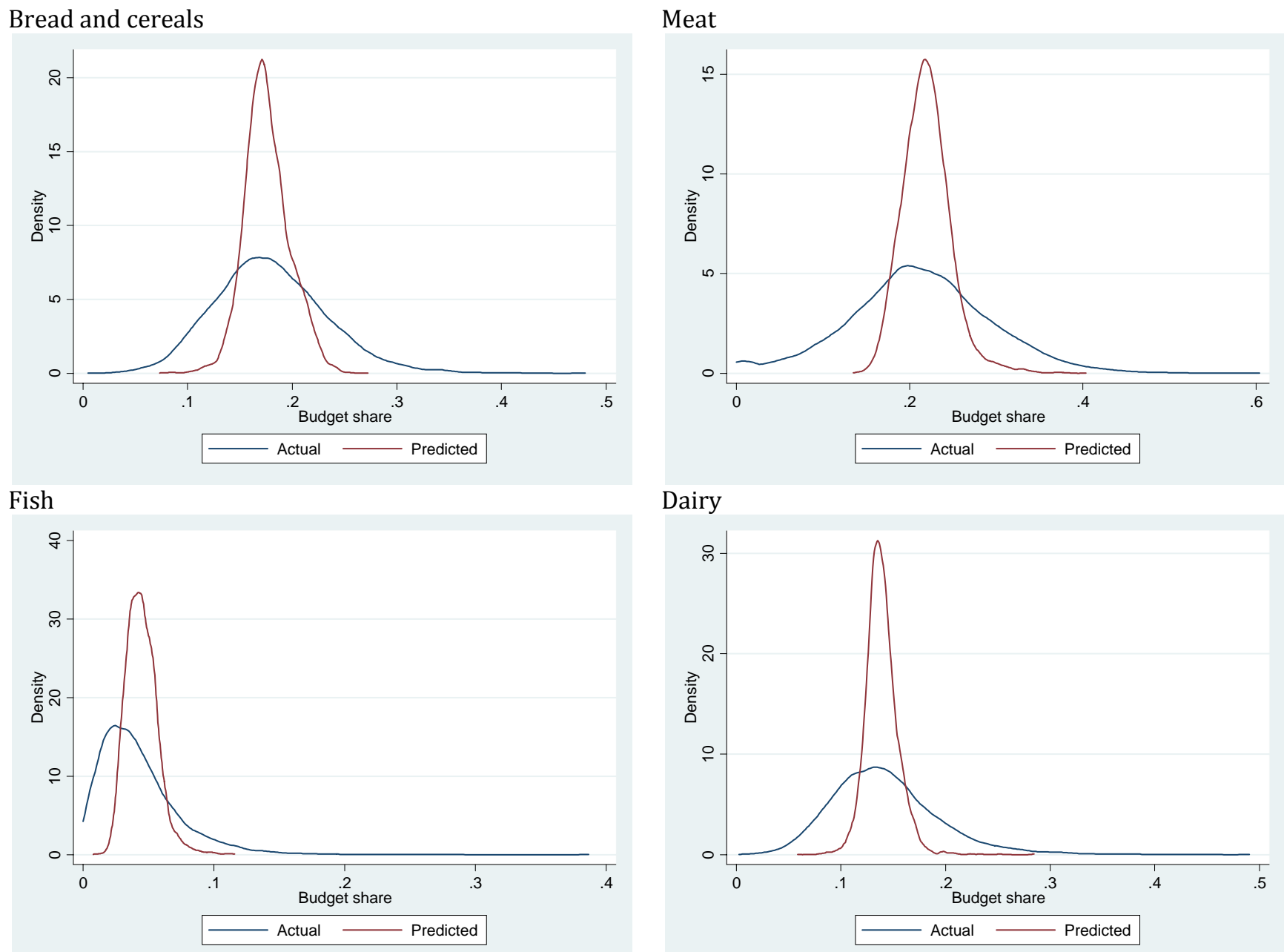

Oils and fats

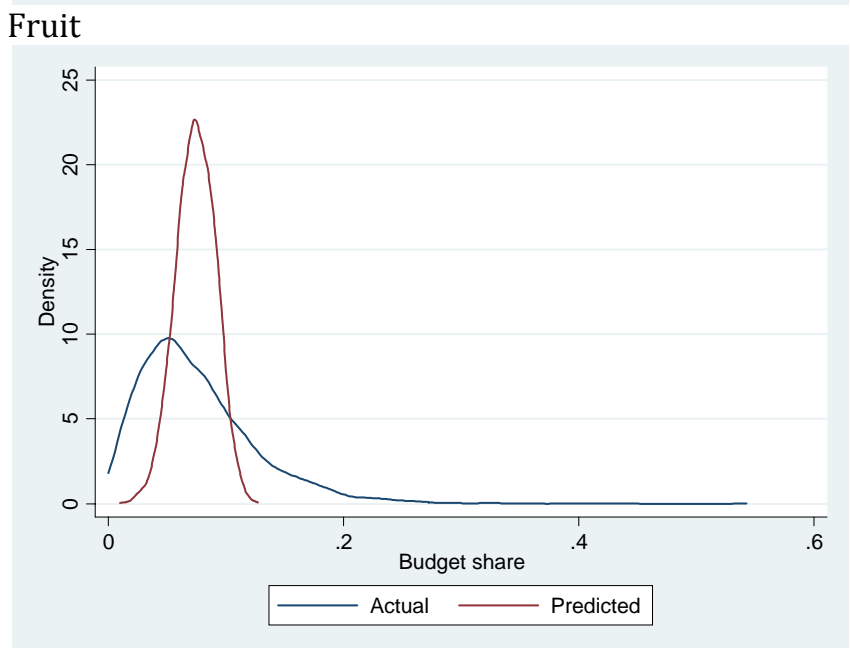


Vegetables

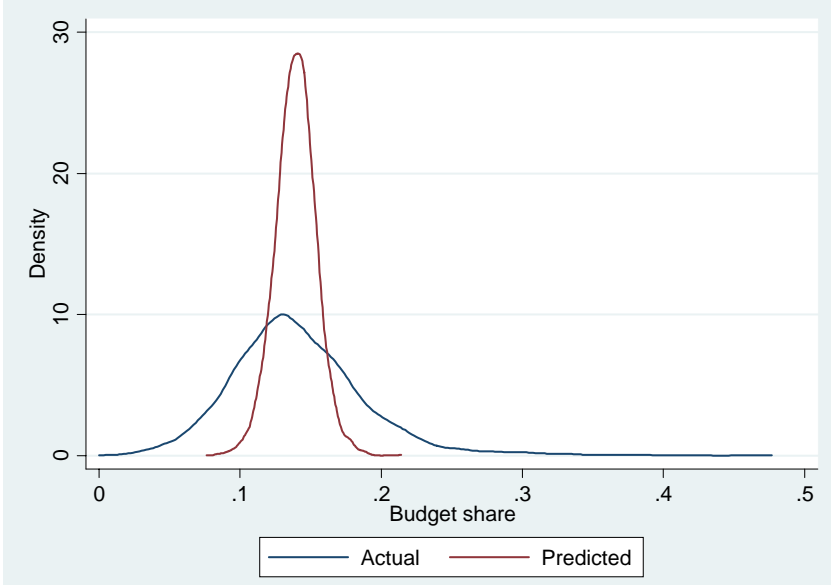

Other food

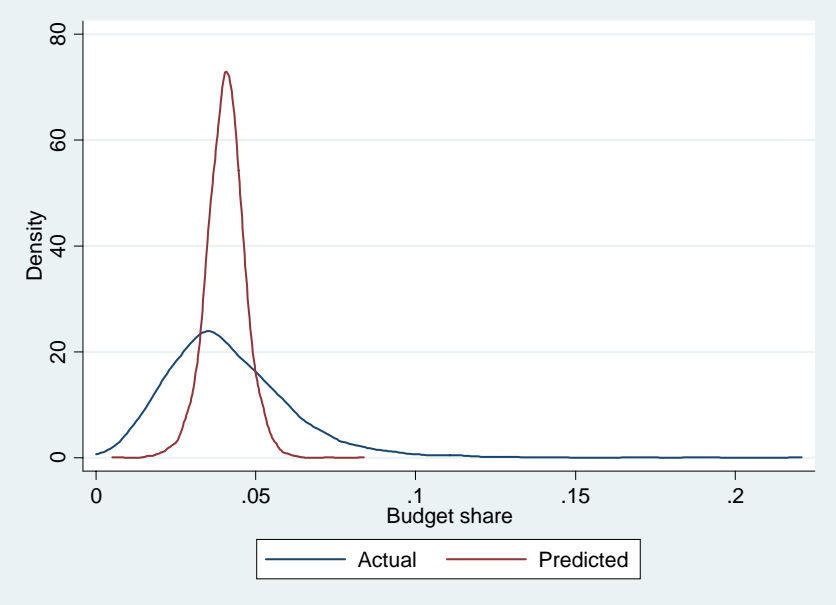

Cold beverages

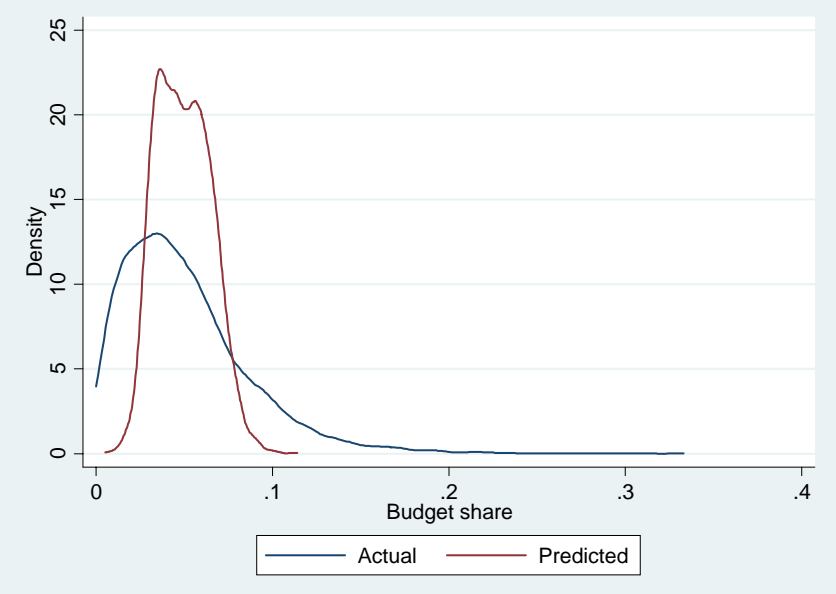

Sugars and confectionery

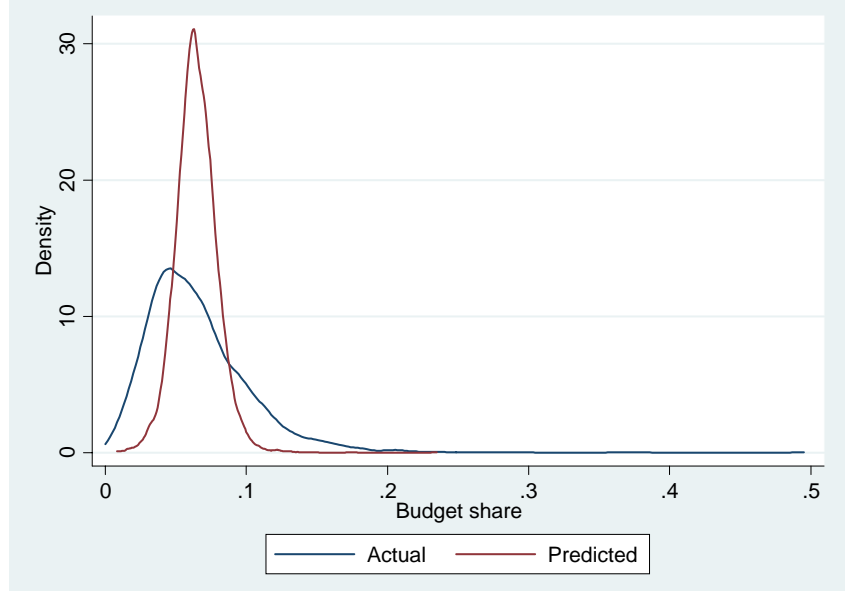

Hot beverages

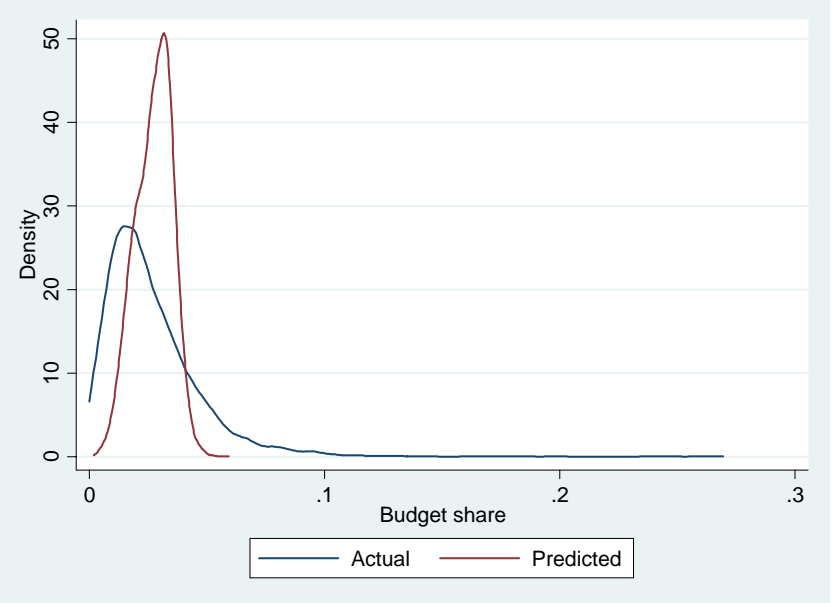

